Western University Scholarship@Western

Department of Economics Research Reports

Economics Working Papers Archive

1991

Liquidity and Market Participation

Stephen D. Williamson

Follow this and additional works at: https://ir.lib.uwo.ca/economicsresrpt

Part of the Economics Commons

Citation of this paper:

Williamson, Stephen D.. "Liquidity and Market Participation." Department of Economics Research Reports, 9110. London, ON:

Department of Economics, University of Western Ontario (1991). 


\section{6}

ISSN : 0318-725X

ISBN : 0-7714-1325-4

\section{RESEARCH REPORT 9110 \\ LIQUIDITY AND MARKET PARTICIPATION \\ by}

Stephen D. Williamson

September 1991

Department of Economics

Social Science Centre

University of Western Ontario

London. Ontario, Canada

N6A $5 \mathrm{C2}$

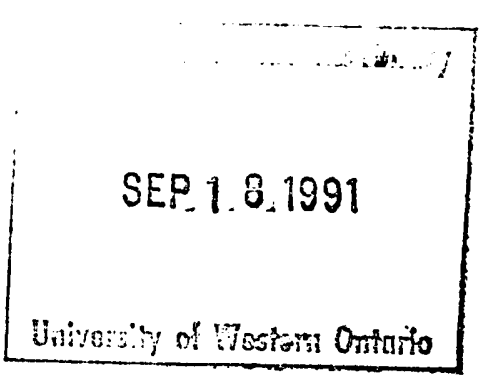




\title{
Liquidity and Market Participation
}

\author{
Stephen D. Williamson \\ Department of Economics \\ University of Western Ontario \\ London, Ontario N6A 5C2, Canada
}

August, 1991

\begin{abstract}
A model of market participation in competitive asset markets is constructed. There are two assets, a liquid asset traded without cost, and an illiquid asset traded subject to fixed transactions costs. Agents have random needs for liquidity, but they are precluded from trading claims contingent on their type, and from diversifying between assets. The model has a participation externality, but in contrast to related work the competitive equilibrium is unique, and there can be an underprovision of Squdilio computational participation in the market for the illiquid asset) in equilibrium. Son
experiments illustrate possible equilibrium outcomes and welfare results.
\end{abstract}

*Financial support from the Lynde and Harry Bradley Foundation is gratefully acknowledged. 


\section{Introduction}

In this paper, a general equilibrium model of participation in aset markets is constructed. There are two assets, a liquid asset which can be traded withont cost, and an illiquid asset for which trading is subject to fixed transactions costs. Agents have random liquidity needs, but are restricted in their ability to diversify across the two assets, and they cannot write contracts insuring against the need for liquidity. The model is used to study the determinants of equilibrium asset market participation, and to examine whether unfettered asset markets supply the appropriate quantity of liquidity.

There is a large literature which studies the provision of liquidity. Probably most familiar to students of monetary economics is work on the optimal quantity of money (see Woodford 1990 for a survey). Many monetary models exhibit a monetary externality; in a competitive equilibrium economic agents tend to economize more than is socially optimal on their holdings of cash balances. Thus, these models tend to exhibit an underprovision of liquidity in equilibrium. The monetary externality can be corrected if cash is forced to bear the same rate of return as riskless interest-bearing assets, either through dellation or the payment of interest on money holdings. The banking model of Diamond and Dybvig (1983) is another example of an environment where too little liquidity can be supplied in equilibrium. In the Diamond-Dybvig model, banks insure agents against random needs for liquidity through deposit contracts which allow for early withdrawal. Given the structure of deposit contracts, there exists a bank run equilibrium where all agents withdraw their deposits. Everyone is worse off in the bank run equilibrium than if they withdrew only when liquidity was required. Thus, the possibility of a bank run represents a failure of the banking system to provide adequate insurance against liquidity needs.

Also related to the model in this paper is a class of models dealing with participation in asset markets and coordination failure (e.g. Chatterjee 1988, Pagano 1989, and Allen and Gale 1991). In these models, agents typically have the choice between participating in a market for a liquid (ristless) asset or in a market for risky equity. The 
more equity market participants, the less volatile are prices in the equity market. Thus, given that investors are risk averee, there can be multiple Pareto-ranked equilibria with differing levels of price volatility in the equity market. If the economg is "stuck" in an inferior equilibrium, there is too much liquidity (relative to equity), which contrasts with the properties of monetary models and of Diamond-Dybvig type banking models discussed above.

The model constructed here is similar in some ways to that in Diamond and Dybvig (1983). Specifically, there are three periods, and agents have uncertain preferences which generate a demand for liquidity. In contrast to Diamond and Dybrig's setup, agents are precluded from making arrangements in the first period to insure against the need for liquidity, but they are permitted to communicate and trade in the middle period. There are two assets, a liquid asset and an illiquid asset. Both assets can be acquired in the first period, and they yield certain returns in the final period. Assets are traded in the middle period. Liquid assets are exchanged at no cost, but agents incur a fixed transactions cost if they either buy or sell an illiquid asset.

A competitive equilibrium always exists and, in contrast to the market participation models discussed above, the equilibrium is unique. Given the nonconverities which fixed transactions costs introduce into each agent's problem, different agents may make different choices in equilibrium, in spite of the fact that all agents are identical in the first period. There exist subsets of the parameter space where only the liquid asset is traded, where only the illiquid asset is traded, and where both are traded. Some intuitively obvious properties hold; in particular, an increase in the costs of exchanging the illiquid asset implies that more liquid assets are held, and a decrease in the rate of return on the illiquid asset leads to less participation in the market for that asset.

Since this is a model with incomplete contingent claims markets, and given what is known about environments with incomplete markets (e.g. Hart 1975 and Geanakoplos and Polemarchakis 1986), we would not expect a competitive equilibrium to be Pareto optimal, in general. Using a notion of constrained Pareto optimality adapted to 
this environment, we show that, if liquidity "matters enough," there excists a region of the parameter space where competitive equilibria are suboptimal. In this region, liquidity is underprovided and there is too much participation in the market for the illiquid asset, relative to the social optimum. This result is quite different from the results in Chatterjee (1988), Pagano (1989), or Allen and Gale (1991), where participation externalities can result in the overprovision of liquidity in equilibrium. In this model, if only the liquid asset is traded in equilibrium, and we consider a small parameter change (such as a reduction in transactions costs) which would cause some agents to trade the illiquid asset, this change in market participation leads to a fall in the price of the liquid asset. Thus, the liquid asset becomes less attractive, and the shift in market participation is self-fulfilling. However, all agents would be better off if they continued to trade only in the market for the liquid asset.

Some computational experiments are used to illustrate possible equilibrium outcomes. Equilibria computed over a parameter grid show that it is possible to support trade in the illiquid asset even given relatively large fixed transactions costs. It is also possible to have equilibria exhibiting trade in both assets over a wide range of transactions costs. If the probability of consuming early (requiring liquidity) is low, then competitive equilibria tend to be constrained Pareto optimal. If the probability of consuming early is high, there can exist a wide range of parameter values for which the illiquid asset is traded (and sometimes only the illiquid asset is traded), but a Pareto improvement would occur if trade in the illiquid asset were completely shut down and all agents traded liquid assets. Thus, if we view this as a model describing when innoration occurs in asset markets, there is a tendency for too much innoration.

The remainder of the paper is organized as follows. In Section 2, the model is constructed, and agents' optimization problems are discussed in Section 3. In Section 4, a competitive equilibrium is defined, the candidate equilibria are determined, and existence and uniqueness of equilibrium is established. Section 5 contains some general results on the optimal provision of liquidity in the model, and Section 6 gives a discusiion of the 
numerical examples. The final rection is a conclusion.

\section{The Model}

There are three periods, 0, 1, and 2, and a continuum of agents with unit mass. Each agent may be one of two types: a type 1 agent consumes in period 1 and has preferences given by $v\left(c_{1}\right)$, and a type 2 agent consumes in period 2 with utility $\nabla\left(c_{2}\right)$, where $c_{1}$ denotes consumption in period $i$. Type 1 agents will be denoted early consumers, and type 2 agents late consumers. The fraction of early consumers in the population is $\pi$, where $0<$ $\pi<1$. Here, $\pi$ is public knowledge in period 0 , but an agent does not learn her type until period 1. Thus, $\pi$ is the probability of consuming early for any agent. It is assumed that $u(\cdot)$ and $\nabla(\cdot)$ are increasing, concave, and unbounded, that $\nabla^{\prime}(0)=u^{\prime}(0)=\infty$, and that $-\mathrm{cu}^{\prime \prime}(\mathrm{c}) / \mathrm{u}^{\prime}(\mathrm{c}) \geq 1$.

In period 0 , each agent receives an endowment of $x_{0}$ units of an investment good, which can be used to produce either of two assets, denoted 1 and 2. Asset $i$ yields a return of $\beta_{i}$ units of the consumption good in period 2 for each unit invested in period 0 . Two restrictions are placed on agents' actions. First, it is assumed that agents are precluded from trading in period 0 , which prevents them from writing contracts contingent on their type, or from setting up "banks" of the type studied in Diamond and Dybrig (1983). That is, an agent cannot insure against the need for liquidity that arises if she is an early consumer. Second, agents cannot diversify between assets 1 and 2. This second restriction is similar to one imposed by Allen and Gale (1991). Limited diversification and limited insurance opportunities are both observed empirically. ${ }^{1}$ However, the reasons for these restrictions are not built into this environment, though it would be straightforward to motivate both restrictions with some simple (though blunt) assumptions about technology and spatial separation. ${ }^{2}$ Also, under some circumstances the restriction on diversification will not be binding.

In period 1, agents learn their types, late consumers each receive an endowment of $x_{1}$ units of the consumption good, and early consumers receive nothing. Thus, early 
consumers wish to trade assets for consumption goods, and late consumers wish to trade consumption goods for assets. Trade in the market for asset 1 is costless, but there are resource costs associated with trading asset 2. We will denote asset 1 the liquid asset, and asset 2 the illiguid asset. If an agent trades the illiquid asset for consumption goods she incurs a fixed cost of $\alpha_{1}$ units of the consumption good. Similarly, an agent exchanging consumption goods for the illiquid asset incurs a fixed cost $a_{2}$. The environment is such that agents cannot share these transactions costs; transactions costs cannot be incurred by an intermediary and spread over many individuals.

The model has at least two interpretations, the first being as a model of participation in an equity market. Here, equity (the illiquid asset) is costly to trade, and thus will be inferior to the liquid asset for early consumers if both assets trade at the same price (which they need not in equilibrium). However, equity is superior to the liquid asset for late consumers if it bears a higher two-period rate of return. Second, the model can be interpreted in terms of banking and currency-holding. Banks hold the illiquid asset and their only role is to facilitate transactions, while an agent can acquire the illiquid asset by taking out a deposit with a bank. Sale or purchase of the illiquid asset is an accounting transaction which requires that both parties to the transaction incur costs of communicating with the bank (through check clearing, for example). If the liquid asset is interpreted as currency, then we are assuming it has a terminal value of $\beta_{1}$ per unit invested in period 0 . However, it would be simple to embed the model in an overlapping generations framework, in which asset 1 was valued fiat money, ${ }^{3}$ and the model would have essentially the same implications.

There are similarities between this model and the banking model constructed by Diamond and Dybvig (1983), in that consumers have uncertain preferences and uncertain demands for liquidity. An important difference is that this model precludes trading among agents in the first period, while Diamond and Dybrig's model closes off communication in the middle period, through a sequential service constraint (see Wallace 1988 for an explicit treatment of sequential service). Also, there is no opportunity in this 
model, where there is in Diamond and Dybvig'n, for one-period storage of the consumption good. The fact that we have closed down a market (the market for insurance against the need for liquidity) gives this model something in common with approaches in the incomplete markets literature (e.g. Hart 1975 and Geanakoplos and Polemarchakis 1986). In contrast though, part of the market structure is determined endogenously here. That is, the asset trading technology, in part, will determine what assets are traded in equilibrium. It may be possible to have equilibria where both assets are traded, where only the liquid asset is traded, or only the illiquid asset is.

\section{Optimization}

Let $q_{1}\left(q_{2}\right)$ denote the price of the liquid (illiquid) asset in terms of the period 1 consumption good. In period 0 , an agent chooses whether to acquire the liquid or the illiquid asset with her endowment of $x_{0}$ units of the investment good. She also chooses how to allocate her period 1 portfolio, contingent on her type. If the agent learns she is an early consumer in period 1 , then she sells her stock of assets, provided transaction costs do not exceed the proceeds from selling, and she then consumes. If she is a late consumer, then the agent enters period 1 with a stock of assets and an endowment of the consumption good, $x_{1}$. Since she will not consume until period 2, the consumption endowment is exchanged for claims to assets. The consumer may also sell some of her stock of assets and buy other assets. Choices are made to maximize expected utility, $\pi u\left(c_{1}\right)+(1-\pi) v\left(c_{2}\right)$. Given the nonconvexities due to the no-diversification restriction in period 0 , and the fixed transactions costs in period 1 , the agent's problem will ultimately involve discrete choice. That is, let $V_{i}$ denote the expected utility in period 0 to producing asset $i$. The consumer then solves

$$
\max \left(V_{1}, V_{2}\right)
$$

where 
(2) $\quad V_{1}=\pi\left(q_{1} x_{0}\right)+(1-\pi) v\left[\max \left(V_{11}, V_{12}\right)\right]$

and

$$
V_{2}=\pi u\left[\max \left(0, q_{2} x_{0}-\alpha_{1}\right)\right]+(1-\pi) v\left[\max \left(V_{21}, V_{22}, V_{23}\right)\right]
$$

with

$$
v_{11}=\beta_{2}\left(q_{1} x_{0}+x_{1}-a_{2}\right) / q_{2}
$$

$$
v_{12}=\beta_{1} x_{0}+\beta_{1} x_{1} / q_{1}
$$

$$
v_{22}=\beta_{1}\left(q_{2} x_{0}+x_{1}-\alpha_{1}\right) / q_{1}
$$

and

$$
v_{23}=\beta_{2} x_{0}+\beta_{2}\left(x_{1}-\alpha_{2}\right) / q_{2}
$$

Suppose an agent produces the liquid asset in period 0 . Then, if she is an early consumer, with probability $\pi$, she consumes $q_{1} x_{0}$ in period 1 [equation (2)]. If she is a late consumer, with probability $1-\pi$, she either incurs the transactions cost, $\alpha_{1}$, and sells her stock of asset 1 and her consumption endowment to buy the illiquid asset, consuming $V_{11}$ in period 2 [equation (4)], or she sells the endowment for the liquid asset and retains the stock of the liquid asset that was acquired in period 0 , consuming $V_{12}$ in period 2 [equation (5)]. Suppose the agent acquires the illiquid asset in period 0 . If she is an early 
consumer, she either sells her stock of sseets, incurring the cost $a_{1}$, or consumes sero [equation (3)]. If she is a late consumer, there are three possible actions that could be taken in period 1. First, she could hold the stock of the illiquid asset acquired in period 0 until period 2, and exchange the period 1 endowment for the liquid asset, consuming $V_{21}$ in period 2 [equation (6)]. Second, the stock of asset 2 and the period 1 endowment could be exchanged for the liquid asset, with a consumption level of $\mathbf{V}_{22}$ in period 2 [equation (7)]. Third, the stock of the illiquid asset from period 0 could be held until the final period and the period 1 endowment exchanged for the illiquid asset, in which case $V_{23}$ is consumed in period 2 [equation (8)].

From (1) $-(3)$, there are eight possible choices an agent could make, where a single choice defines the asset acquired in period 0 and actions taken in period 1 contingent on type (early or late consumer). Let $U_{j}\left(q_{1}, q_{2}\right)$ denote the expected utility the agent achieves by taking choice $j$, given prices, where $j=1,2,3, \ldots$. From (1) $-(3)$, these expected utilities are defined as follows.

$$
\begin{aligned}
& U_{1}\left(q_{1}, q_{2}\right) \equiv \pi\left(q_{1} x_{0}\right)+(1-\pi) v\left(V_{11}\right), \\
& U_{2}\left(q_{1}, q_{2}\right) \equiv \pi\left(q_{1} x_{0}\right)+(1-\pi) v\left(V_{12}\right), \\
& U_{3}\left(q_{1}, q_{2}\right) \equiv \pi(0)+(1-\pi) v\left(V_{21}\right), \\
& U_{4}\left(q_{1}, q_{2}\right) \equiv \pi(0)+(1-\pi) v\left(V_{22}\right), \\
& U_{5}\left(q_{1}, q_{2}\right) \equiv \pi v(0)+(1-\pi) v\left(V_{23}\right), \\
& U_{6}\left(q_{1}, q_{2}\right) \equiv \pi u\left(q_{2} x_{0}-\alpha_{1}\right)+(1-\pi) v\left(V_{21}\right), \\
& U_{7}\left(q_{1}, q_{2}\right) \equiv \pi\left(q_{2} x_{0}-\alpha_{1}\right)+(1-\pi) v\left(V_{22}\right),
\end{aligned}
$$




$$
U_{8}\left(q_{1}, q_{2}\right) \equiv \pi\left(q_{2} x_{0}-a_{1}\right)+(1-\pi) v\left(V_{23}\right)
$$

Note that all choices are not feasible given prices $q_{1}$ and $q_{2}$. For a particular choice $j$ to be feasible, consumption must be nonnegative in each period. For example, choice 6 is not feasible if $q_{2} x_{0}-\alpha_{1}<0$ (consumption is negative in period 1 if the agent consumes early), and choice 8 is not feasible if $x_{1}-a_{2}<0$ (consumption is negative in period 1 if the agent consumes late). Let $S_{f}$ denote the set of feasible choices, where $S_{f} c$ $\{1,2,3, \ldots, 8\}$.

\section{Competitive Equilibrium}

Given the nonconvexities in each agent's problem, we need to allow for the possibility that there may not be a unique choice which maximizes expected utility given equilibrium prices, and that different agents may make different equilibrium choices. Let $p_{\mathbf{j}}$ denote the fraction of agents who make choice $j$.

Definition. A competitive equilibrium is given by $\dot{q}_{i}, \dot{p}_{j}, i=1,2, j=1,2, \ldots, 8$, such that with $q_{i}=\dot{q}_{i}, p_{j}=\dot{p}_{j}, i=1,2, j=1,2, \ldots 8$,

$$
q_{1}\left(p_{1}+\pi p_{2}\right) x_{0}=(1-\pi)\left[\left(p_{2}+p_{3}+p_{6}\right) x_{1}+\left(p_{4}+p_{7}\right)\left(q_{2} x_{0}+x_{1}-a_{1}\right)\right]
$$

[market clearing for the liquid asset in period 1 ]

$$
\begin{aligned}
& q_{2}\left[\pi\left(p_{6}+p_{7}+p_{8}\right)+(1-\pi)\left(p_{4}+p_{7}\right)\right] x_{0} \\
& =(1-\pi)\left[p_{1}\left(q_{1} x_{0}+x_{1}-a_{2}\right)+\left(p_{5}+p_{8}\right)\left(x_{1}-a_{2}\right)\right]
\end{aligned}
$$

[market clearing for the illiquid asset in period 1 ]

$$
\underset{j}{\sum_{j}} p_{j}=1
$$


(20)

$$
q_{i} \geq 0,0 \leq p_{j} \leq 1, i=1,2, j=1,2, \ldots 8
$$

If $p_{j}>0$ then $U_{j}\left(q_{1}, q_{2}\right) \geq U_{k}\left(q_{1}, q_{2}\right)$ for all $k \in S_{F}$ [equilibrium choices are weakly preferred to all feasible choices]

In the period 1 market-clearing conditions for the two assets, (17) and (18), the left side of each equation represents the quantity of consumption goods received in period 1 by sellers of the asset, and the right side the quantity of consumption goods, net of transactions costs, exchanged by buyers of the asset. For example, in equation (17), agents making choice 1 (fraction $p_{1}$ of the population) acquire the liquid asset in period 0 and then sell it under all contingencies in period 1. If an agent makes choice 2, the liquid asset is acquired, but sold only if the agent consumes early (with probability $\pi$ ). Thus, on the left side of (17), $p_{1}+\pi p_{2}$ is the fraction of the population selling the liquid asset, and each seller receives $q_{1} x_{0}$ units of the consumption good. Agents buying the liquid asset are all late consumers. On the right side of (17), the fraction of the population exchanging their endowment for the liquid asset is $(1-\pi)\left(p_{2}+p_{3}+p_{6}\right)$, and each of these agents has an endowment of $x_{1}$ units of the consumption good. Some agents [fraction $(1-\pi)\left(p_{4}+p_{7}\right)$ of the population] sell their holdings of the illiquid asset and their endowment (each agent exchanges $q_{2} x_{0}+x_{1}-\alpha_{1}$ units of the consumption good, net of transactions costs) for the liquid asset.

\subsection{Candidate Equilibria}

As a first step in determining competitive equilibria, it is useful to eliminate types of candidate equilibria where choices are clearly inconsistent with (17) $-(21)$. Let $S=\left\{j: p_{j}\right\rangle$ 0\} denote the set of choices made by a positive number of agents in equilibrium, where S C $S_{f}$ First, it helps to show that the price of the liquid asset must be strictly positive in equilibrium. 
Lemme 1. In a competitive equilibrium, $q_{1}>0$.

Proof: Suppose $q_{1}=0$. Then from (17), we have $p_{2}=p_{3}=p_{4}=p_{6}=p_{7}=0$. Then, from (11), at least one of $p_{1}, p_{5}$, or $p_{8}$ must be positive. If $x_{1}<a_{2}$, then choice $j$ is not feasible for $j=1,5$, or 8 , a contradiction. If $x_{1}=a_{2}$, then $q_{2}=0$, from (18). Choice 8 is then not feasible, $80 P_{8}=0$. From (9), (10), (11), and (13), (21) does not hold for $j=5$ and $k=2$, and for $j=1$ and $k=2$, a contradiction. If $x_{1}>a_{2}$, then from (18) $a_{2}>0$, and (21) does not hold for $j=1$ and $k=2$, for $j=5$ and $k=3$, and for $j=8$ and $k=7$. Q.E.D.

Essentially, Lemma 1 states that, if the price of the liquid asset were zero in period 1, this would imply an infinite one-period rate of return to holding the liquid asset from period 1 to period 2. Optimixing choices would then imply excess demand for the liquid asset in period 1.

Proposition $1.3 \& \mathrm{~S}, 4 \notin \mathrm{S}, 5$ \&S.

Proof. Suppose that $3 \in \mathrm{S}, 80$ that $P_{3}>0$. Given Lemma $1,(21)$ does not hold for $j=3$ and $k=2$, a contradiction. Similar arguments apply if $4 \in S$ or $5 \in$ S. Q.E.D.

The logic behind Proposition 1 is the following. Choices 3, 4, and 5 imply zero consumption for early consumers. But, since the price of the liquid asset is positive in equilibrium and $u^{\prime}(0)=\Phi$, choices 3,4 , and 5 are always dominated by choice 2 .

Proposition 2. 7 \& S.

Proof. Suppose that $p_{7}>0$. Then, $(21)$ implies that $U_{6}\left(q_{1}, q_{2}\right) \leq U_{7}\left(q_{1}, q_{2}\right)$. Therefore, $\beta_{1} / q_{1}>\beta_{2} / q_{2}$. Therefore, $U_{2}\left(q_{1}, q_{2}\right)>U_{1}\left(q_{1}, q_{2}\right)$ and $U_{6}\left(q_{1}, q_{2}\right)>U_{8}\left(q_{1}, q_{2}\right)$, which implies, from (21), that $p_{1}=p_{8}=0$. Since $p_{7}>0$ implies $q_{2}>0$ (for feasibility), and given Lemma $1,(18)$ does not hold, a contradiction. Q.E.D. 
From Propositions 1 and 2, choices 1 and 7 cannot be equilibrium choices. That is, agents will never choose, in equilibrium, to sell the illiquid asset to buy the liquid asset, if they are late consumers. If an agent acquires the illiquid asset in period 0 and is a late consumer, the illiquid asset will be held until the final period, as with choices 6 and 8 .

Proposition 3. $S \neq\{1\}, S \neq\{6\}, S \neq\{1,8\}, S \neq\{6,8\}, S \neq\{1,2\}, S \neq\{2,6\}$.

Proof. If $S=\{1\}$, or $S=\{6\}$, or $S=\{1,8\}$, or $S=\{6,8\}$, then (17) does not hold given Lemma 1 , a contradiction. If $S=\{1,2\}$, or $S=\{2,6\}$, then feasibility implies that $q_{2}>0$, but then (18) does not hold, a contradiction. Q.E.D.

Proposition 3 deals with cases where candidate equilibrium choices imply that there are sellers in an asset market and no buyers, or vice versa, thus violating market clearing.

Proposition 4. $S \neq\{2,8\}, S \neq\{1,2,8\}, S \neq\{2,6,8\}, S \neq\{1,2,6,8\}$.

Proof. Suppose that $S=\{2,8\}$. Then (21) holds for $j=8$ and $k=6$, and for $j=2$ and $k=$ 1, or

$$
\left(\beta_{2} / q_{2}-\beta_{1} / q_{1}\right) x_{1} \geq \beta_{2} \alpha_{2} / q_{2}
$$

and

$$
\left(\beta_{2} / q_{2}-\beta_{1} / q_{1}\right)\left(q_{1} x_{0}+x_{1}\right) \leq \beta_{2} \alpha_{2} / q_{2} .
$$

But (22) implies that $\beta_{2} / q_{2}-\beta_{1} / q_{1}>0$. Therefore, $\left(\beta_{2} / q_{2}-\beta_{1} / q_{1}\right)\left(q_{1} x_{0}+x_{1}\right)>$ $\beta_{2} \alpha_{2} / q_{2}$, a contradiction. Now, suppose that $S=\{1,2,8\}$. Given $(21)$ and $(22)$, the following equality must hold.

$$
\left(\beta_{2} / q_{2}-\beta_{1} / q_{1}\right)\left(q_{1} x_{0}+x_{1}\right)=\beta_{2} a_{2} / q_{2}
$$


But (22) implies that $\left(\beta_{2} / q_{2}-\beta_{1} / q_{1}\right)\left(q_{1} x_{0}+x_{1}\right)>\beta_{2} \alpha_{2} / q_{2}$, contradiction. Next, suppose that $S=\{2,6,8\}$. Then (23) must hold, in addition to

$$
\left(\beta_{2} / q_{2}-\beta_{1} / q_{1}\right) x_{1}=\beta_{2} a_{2} / q_{2}
$$

But (25) implies that $\left(\beta_{2} / q_{2}-\beta_{1} / q_{1}\right)\left(q_{1} x_{0}+x_{1}\right)>\beta_{2} \alpha_{2} / q_{2}$, a contradiction. Last, suppose that $S=\{1,2,6,8\}$. Then (22) and (23) must both hold with equality. Therefore $\beta_{2} / q_{2}-\beta_{1} / q_{1}>0$, but then Lemma 1 implies that (22) and (23) cannot both hold with equality, a contradiction. Q.E.D.

Proposition 4 deals with some cases which violate optimality.

From Propositions 1-4, we are left with five possibilities in equilibrium. These are: $S=\{2\}, S=\{8\}, S=\{1,6\}, S=\{1,2,6\}$, and $S=\{1,6,8\}$. We will denote each case by the set $S$ that corresponds to each. Note that equilibrium choices are either $1,2,6$, or 8. The fraction of agents acquiring the liquid asset in period 0 is $p_{1}+p_{2}$, and the fraction acquiring the illiquid asset is $p_{6}+p_{8}$. Equilibrium $\{2\}$ has all agents acquiring and trading the liquid asset, in equilibrium $\{8\}$ all agents acquire and trade the illiquid asset, and in equilibria $\{1,6\},\{1,2,6\}$, and $\{1,6,8\}$ both assets are acquired and traded.

Note that the equilibria with trade in both assets involve some agents holding the liquid asset from period 0 to period 1 , and then holding the illiquid asset from period 1 to period 2 if they are late consumers (choice 1), while some other agents hold illiquid assets from period 0 to period 1 and then hold liquid assets from period 1 to period 2 if they are late consumers (choice 6). The agent making choice 1 acquires the liquid asset in period 0 as insurance against the possibility of being an early consumer. If it turns out she is a late consumer, the need for holding the liquid asset is gone and she reallocates her portfolio to the illiquid asset. An agent acquiring the illiquid asset in period 0 would make a smaller transaction in period 1 than would the choice 1 agent, if she chose to hold only 
the illiquid asset until the final period. Thus, given the fixed transactions costs, it coold be consistent for some agents to make choice 1 and some to make choice 6 in equilibrium.

\subsection{Uniqueness of Candidate Equilibria Within Each Class}

Having established five types of candidate competitive equilibria in the previous subsection, we now show, through a series of propositions, that each type of candidate equilibrium is unique, within its class, if it exists. Further, we establish necessary and sufficient conditions for the existence of each type of candidate equilibrium.

\section{Equilibrium \{2\}}

Here, $p_{2}=1$ and $p_{j}=0$ for $j=2,3, \ldots, 8$. From the market-clearing condition, (17), we can then solve for the price of the liquid asset to get

$$
q_{1}=(1-\pi) x_{1} / \pi x_{0}
$$

Proposition 5. Equilibrium $\{2\}$ is essentially unique (within its class), if it exists, and exists if and only if

$$
\begin{gathered}
\pi u\left([1-\pi] x_{1} / \pi\right)+(1-\pi) v\left(\beta_{1} x_{0} /[1-\pi]\right) \geq \pi u\left(\beta_{2}\left[x_{1}-\pi \alpha_{2}\right][1-\pi] / \beta_{1} \pi-\alpha_{1}\right) \\
+(1-\pi) v\left(\beta_{2} x_{0}+\beta_{1} x_{0} \pi /[1-\pi]\right) .
\end{gathered}
$$

Proof: See the appendix.

What is meant by "essential" uniqueness in Proposition 5 is that expected utility, quantities, and the price of the liquid asset (from (26)) are uniquely determined, but $q_{2}$, the price of the illiquid asset, is not. However, in equilibrium $\{2\}$, there are no trades executed at the price $q_{2}$, so that this source of nonuniqueness is inconsequential. 


\section{Equilibrium \{8\}}

In equilibrium $\{8\}$, we have $p_{8}=1$ and $p_{j}=0$ for $j=1,2,3, \ldots$. Then, from (18), the equilibrinm price of the illiquid asset is

$$
q_{2}=(1-\pi)\left(x_{1}-a_{2}\right) / \pi x_{0}
$$

Proposition 6. Equilibrium \{8\} is essentially unique (within its class) if it exists, and exists if and only if

$$
\begin{aligned}
& \pi u\left([1-\pi]\left[x_{1}-\alpha_{2}\right] / \pi-\alpha_{1}\right)+(1-\pi) v\left(\beta_{2} x_{0} /[1-\pi]\right) \\
& \geq \pi u\left(\beta_{1} x_{1}[1-\pi] / \pi \beta_{2}\right)+(1-x) v\left(\beta_{1} x_{0} x_{1} /\left[x_{1}-\alpha_{2}\right]+\beta_{2} \pi x_{0} /[1-\pi]\right) .
\end{aligned}
$$

Proof. See the appendix.

As with equilibrium $\{2\}$, equilibrium $\{8\}$ is unique if it exists, except that $q_{1}$, the price of the liquid asset, is in general not uniquely determined. As was the case with the illiquid asset in equilibrium $\{2\}$, the liquid asset is not traded here, so there is uniqueness for everything which is essential.

Equilibrium $\{1,6\}$

Here, $p_{1}>0, p_{6}>0$, and $p_{j}=0$ for $j=2,3,4,5,6$ and 8. Then, from (17) we get

$$
q_{1}=(1-\pi) p_{6} x_{1} / p_{1} x_{0}
$$

and, from (18) and (26),

$$
q_{2}=(1-x) p_{1}\left(x_{1}-a_{2}\right) / \pi p_{6} x_{0}+(1-x)^{2} x_{1} / \pi x_{0}
$$


Since $p_{i}>0$ for $i=1,6$, then (21) must bold with equality for $j=1$ and $k=6$ or, using (9), (14), (30) and (31),

$$
\begin{aligned}
& \pi\left([1-\pi] p_{6} x_{1} / p_{1}\right)+(1-\pi) v\left(\beta_{2} \pi x_{0} p_{6} /[1-\pi] p_{1}\right) \\
& =\pi u\left([1-\pi] p_{1}\left[x_{1}-a_{2}\right] / \pi p_{6}+[1-\pi]^{2} x_{1} / \pi-\alpha_{1}\right)+(1-\pi) v\left(\beta_{2} x_{0}+\beta_{1} x_{0} p_{1} / p_{6}[1-\pi]\right)
\end{aligned}
$$

From (19), we must have

$$
p_{1}+p_{6}=1
$$

The values of $p_{1}, p_{6}, q_{1}$, and $q_{2}$ which solve (30)-(33) constitute an equilibrium.

Proposition 7. If equilibrium $\{1,6\}$ exists, it is unique within its class. Further, equilibrium $\{1,6\}$ exists if and only if

$$
\begin{aligned}
& \pi u\left([1-\pi] \nabla x_{1}\right)+(1-\pi) v\left(\beta_{1} x_{0}+\beta_{1} x_{0} /[1-\pi] \theta\right) \\
& \leq \pi\left(\beta_{2}[1-\pi] \sigma\left[x_{1}-\alpha_{2}\right] / \beta_{1}-\alpha_{1}\right)+(1-\pi) v\left(\beta_{2} x_{0}+\beta_{1} \pi x_{0} /[1-\pi] \theta\right)
\end{aligned}
$$

and

$$
\begin{aligned}
& \pi u\left([1-\pi] x_{1} \theta\right)+(1-\pi) v\left(\beta_{1} x_{0} x_{1} /\left[x_{1}-\alpha_{2}\right]+\beta_{1} x_{0} \pi /[1-\pi] \theta\right) \\
& \geq \pi u\left(\beta_{2}\left[x_{1}-\alpha_{2}\right][1-\pi] \theta / \beta_{1} \pi-\alpha_{1}\right)+(1-\pi) v\left(\beta_{2} x_{0}+\beta_{1} \pi x_{0} /[1-\pi] \phi\right),
\end{aligned}
$$

where

$$
\ell \equiv\left\{\beta_{1}(1-\pi)+\left[\beta_{1}^{2}(1-\pi)^{2}+4 \beta_{1} \beta_{2} \pi\right]^{1 / 2}\right\} / 2 \beta_{2} \pi
$$


(37)

$$
\theta \equiv\left\{\beta_{1}(1-\pi) x_{1}+\left\{\beta_{1}^{2}(1-\pi)^{2} x_{1}^{2}+4 \pi \beta_{1} \beta_{2}\left(x_{1}-a_{2}\right)^{2}\right\}^{1 / 2}\right\} / 2 \pi \beta_{2}\left(x_{1}-a_{2}\right) .
$$

Proof. See the appendix.

Equilibrium $\{1,2,6\}$

With equilibrium $\{1,2,6\}, p_{1}>0, p_{2}>0, p_{6}>0$, and $p_{j}=0$ for $j=3,4,5,6,7$, and 8 .

From (17), we get

$$
q_{1}=(1-\pi)\left(p_{2}+p_{6}\right) x_{1} /\left(p_{1}+\pi p_{2}\right) x_{0}
$$

and, from (18),

$$
q_{2}=(1-\pi) p_{1}\left(x_{1}-a_{2}\right) / \pi p_{6} x_{0}+(1-\pi)^{2} p_{1}\left(p_{2}+p_{6}\right) x_{1} / \pi p_{6}\left(p_{1}+\pi p_{2}\right) x_{0}
$$

Here, (21) must hold with equality for $j=1$ and $k=2$, that is

$$
q_{2}=\beta_{2}\left(q_{1} x_{0}+x_{1}-\alpha_{2}\right) /\left(\beta_{1} x_{0}+\beta_{1} x_{1} / q_{1}\right) .
$$

Also, (21) must hold for $j=2$ and $k=6$, or, using (40) to substitute for $q_{2}$,

$$
\begin{aligned}
& \pi u\left(q_{1} x_{0}\right)-\pi u\left(\beta_{2}\left[q_{1} x_{0}+x_{1}-a_{2}\right] q_{1} x_{0} / \beta_{1}\left[q_{1} x_{0}+x_{1}\right]-a_{1}\right) \\
& =(1-\pi) v\left(\beta_{2} x_{0}+\beta_{1} x_{1} / q_{1}\right)-(1-\pi) v\left(\beta_{1} x_{0}+\beta_{1} x_{1} / q_{1}\right)
\end{aligned}
$$

From (19) and (38) $-(40)$, we can then solve for $p_{6}, p_{1}$, and $p_{2}$ in terms of $q_{1}$ as follows:

$$
P_{6}=\left(\beta_{1} / \beta_{2}\right)\left[(1-\pi) x_{1}-\pi q_{1} x_{0}\right] / x\left[1-\left(\beta_{1} / \beta_{2}\right)\right] q_{1} x_{0}
$$


(43)

$$
p_{1}=\left[(1-\pi) x_{1}-\pi q_{1} x_{0}\right] /(1-x)\left[1-\left(\beta_{1} / \beta_{2}\right)\right]\left(q_{1} x_{0}+x_{1}\right)
$$

(44) $\quad P_{2}=1-P_{1}-P_{6}$.

Equilibrium $\{1,2,6\}$ is the solution to (40)-(44) for $q_{1}, q_{2}, p_{1}, p_{2}$, and $p_{6}$.

Proposition 8. Equilibrium $\{1,2,6\}$ is unique (within its class), if it exists, and it exists if and only if

$$
\begin{aligned}
& \pi\left(g_{1} x_{0}\right)-\pi\left(\beta_{2}\left[g_{1} x_{0}+x_{1}-\alpha_{2}\right] g_{1} x_{0} / \beta_{1}\left[a_{1} x_{0}+x_{1}\right]-\alpha_{1}\right) \\
& >(1-\pi) v\left(\beta_{2} x_{0}+\beta_{1} x_{1} / g_{1}\right)-(1-\pi) v\left(\beta_{1} x_{0}+\beta_{1} x_{1} / g_{1}\right),
\end{aligned}
$$

and

$$
\begin{aligned}
& \pi\left(\bar{q}_{1} x_{0}\right)-\pi u\left(\beta_{2}\left[\bar{q}_{1} x_{0}+x_{1}-a_{2}\right] \bar{q}_{1} x_{0} / \beta_{1}\left[\bar{q}_{1} x_{0}+x_{1}\right]-\alpha_{1}\right) \\
& <(1-\pi) v\left(\beta_{2} x_{0}+\beta_{1} x_{1} / \bar{q}_{1}\right)-(1-\pi) v\left(\beta_{1} x_{0}+\beta_{1} x_{1} / \bar{q}_{1}\right),
\end{aligned}
$$

where

$$
q_{1} \equiv\left\{(1-\pi)^{2} \beta_{1} x_{1}+\left[(1-\pi)^{4} \beta_{1}^{2} x_{1}^{2}+4 \pi \beta_{2}(1-\pi)^{2} \beta_{1} x_{1}^{2}\right]^{1 / 2}\right\} / 2 \pi \beta_{2} x_{0}
$$

and

$$
\bar{q}_{1} \equiv(1-\pi) x_{1} / \pi x_{0}
$$

Proof. See the appendix. 


\section{Bquilibrium $\{1,6,8\}$}

Here, $p_{1}>0, p_{6}>0, p_{8}>0$, and $p_{j}=0$ for $j=1,3,4,5$, and 7. From (17), we get

$$
q_{1}=(1-\pi) p_{6} x_{1} / p_{1} x_{0}
$$

and, from (18),

$$
q_{2}=(1-\pi)\left(p_{1}+p_{8}\right)\left(x_{1}-a_{2}\right) / \pi\left(p_{6}+p_{8}\right) x_{0}+(1-\pi)^{2} p_{6} x_{1} / x\left(p_{6}+p_{8}\right) x_{0} .
$$

Given $p_{6}>0$ and $p_{8}>0,(21)$ must hold with equality for $j=6$ and $k=8$, that is, using (14) and (16),

$$
\beta_{1} x_{1} / q_{1}=\beta_{2}\left(x_{1}-a_{2}\right) / q_{2}
$$

Similarly, (21) holds with equality for $j=1$ and $k=6$, which gives, using (9) and (14), using (51) to substitute for $q_{2}$, and rearranging,

$$
\begin{aligned}
& \pi u\left(q_{1} x_{0}\right)-\pi u\left(\beta_{2}\left(x_{1}-\alpha_{2}\right) q_{1} x_{0} / \beta_{1} x_{1}-\alpha_{1}\right) \\
& =-(1-\pi) v\left(\beta_{1} x_{1} x_{0} /\left[x_{1}-\alpha_{2}\right]+\beta_{1} x_{1} / q_{1}\right)+(1-\pi) v\left(\beta_{2} x_{0}+\beta_{1} x_{1} / q_{1}\right) .
\end{aligned}
$$

From (19), (49), (50), and (51), we can solve for $p_{1}, p_{6}$, and $p_{8}$, given $q_{1}$, as follows

$$
\begin{aligned}
P_{6}= & {\left[(1-\pi)\left(x_{1}-\alpha_{2}\right)-q_{1} x_{0} \beta_{2} \pi\left(x_{1}-\alpha_{2}\right) / \beta_{1} x_{1}\right] } \\
& \div\left[(1-\pi)\left(x_{1}-\alpha_{2}\right)-(1-\pi) \pi \beta_{2}\left(x_{1}-\alpha_{2}\right) / \beta_{1}-(1-\pi)^{2} x_{1}\right]
\end{aligned}
$$

$$
p_{1}=(1-\pi) x_{1} p_{6} / q_{1} x_{0}
$$

$$
p_{8}=1-p_{1}-P_{6}
$$


Equilibrium $\{1,6,8\}$ is the solution to $(51)-(55)$ for $q_{1}, q_{2}, P_{1}, P_{6}$, and $P_{8}$.

Proposition 9. Equilibrium $\{1,6,8\}$ is unique (within its class), if it exists. Further, equilibrium $\{1,6,8\}$ exists if and only if

$$
\begin{aligned}
& \pi\left(q_{1} x_{0}\right)-\pi u\left(\beta_{2}\left(x_{1}-\alpha_{2}\right) q_{1} x_{0} / \beta_{1} x_{1}-\alpha_{1}\right) \\
& >-(1-\pi) v\left(\beta_{1} x_{1} x_{0} /\left[x_{1}-\alpha_{2}\right]+\beta_{1} x_{1} / q_{1}\right)+(1-\pi) v\left(\beta_{2} x_{0}+\beta_{1} x_{1} / q_{1}\right)
\end{aligned}
$$

and

$$
\begin{aligned}
& \pi u\left(\dot{q}_{1} x_{0}\right)-\pi\left(\beta_{2}\left(x_{1}-\alpha_{2}\right) \dot{q}_{1} x_{0} / \beta_{1} x_{1}-\alpha_{1}\right) \\
& <-(1-\pi) v\left(\beta_{1} x_{1} x_{0} /\left[x_{1}-\alpha_{2}\right]+\beta_{1} x_{1} / \dot{q}_{1}\right)+(1-\pi) v\left(\beta_{2} x_{0}+\beta_{1} x_{1} / \dot{q}_{1}\right)
\end{aligned}
$$

where

$$
\underline{q}_{1} \equiv \beta_{1}(1-\pi) x_{1} / \beta_{2} \pi x_{0}
$$

and

$$
\begin{aligned}
\bar{q}_{1} \equiv & \left\{(1-x)^{2} x_{1}^{2}+\left[(1-\pi)^{4} x_{1}^{4}+4 \beta_{2} x_{1}^{2}\left(x_{1}-\alpha_{2}\right)^{2}(1-x)^{2} \pi / \beta_{1}\right]^{1 / 2}\right\} \\
& \times \beta_{1} / 2 \beta_{2}\left(x_{1}-\alpha_{2}\right) x_{0} \pi .
\end{aligned}
$$

Proof: See the appendix.

\subsection{Bristence and Oniqueness of Equilibrium}

We have established that there are potentially five types of equilibria. Further, there can 
be at most one of each type of equilibrium. Finally, Propositions $5-0$ give necessary and sufficient conditions for the existence of each type of equilibrium. Now, we will show that an equilibrium always exists, and that it is unique. That is, at least one type of equilibrium exists, and no two types of equilibria coexist.

Define $W(S)$ to be the subset of the parameter space for which an equilibrium of type $S$ exists, $S=\{2\},\{8\},\{1,6\},\{1,2,6\},\{1,6,8\}$. From (27), (29), (30), (34) $-(38)$, $(45)-(49)$, and $(56)-(59)$, we get the following:

$$
\begin{aligned}
& W(\{2\})=\left\{\phi: F^{1}(\phi) \geq 0\right\}, \\
& W(\{8\})=\left\{\phi: F^{4}(\phi) \leq 0\right\}, \\
& W(\{1,6\})=\left\{\phi: F^{2}(\phi) \leq 0, F^{3}(\phi) \geq 0\right\}, \\
& W(\{1,2,6\})=\left\{\phi: F^{1}(\phi)<0, F^{2}(\phi)>0\right\}, \\
& W(\{1,6,8\})=\left\{\phi: F^{3}(\phi)<0, F^{4}(\phi)>0\right\}
\end{aligned}
$$

Here, $\phi \equiv\left(\pi, x_{0}, x_{1}, \alpha_{1}, \alpha_{2}, \beta_{1}, \beta_{2}\right)$ is the parameter vector, and the functions $F^{i}(\phi), i=1,2,3,4$, are defined as follows:

$$
\begin{aligned}
& F^{1}(\phi) \equiv \pi\left([1-\pi] x_{1} / \pi\right)+(1-\pi) v\left(\beta_{1} x_{0} /[1-\pi]\right)-\pi v\left(\beta_{2}\left[x_{1}-\pi a_{2}\right][1-\pi] / \beta_{1} \pi-a_{1}\right) \\
& -(1-\pi) v\left(\beta_{2} x_{0}+\beta_{1} x_{0} \pi /[1-\pi]\right) \text {, } \\
& F^{2}(\phi) \equiv \pi\left(q_{1} x_{0}\right)+(1-\pi) v\left(\beta_{2} x_{0}+\beta_{1} x_{1} / g_{1}\right) \\
& -\pi u\left(\beta_{2} q_{1} x_{0}\left[a_{1} x_{0}+x_{1}-\alpha_{2}\right] / \beta_{1}\left[a_{1} x_{0}+x_{1}\right]-\alpha_{1}\right)-(1-\pi) v\left(\beta_{2} x_{0}+\beta_{1} x_{1} / q_{1}\right), \\
& F^{3}(\phi) \equiv \pi\left(\dot{q}_{1} x_{0}\right)+(1-\pi) v\left(\beta_{1} x_{0} x_{1} /\left[x_{1}-\alpha_{2}\right]+\beta_{1} x_{1} / \dot{q}_{1}\right) \\
& -\pi\left(\beta_{2}\left[x_{1}-\alpha_{2}\right] \dot{q}_{1} x_{0} / x_{1} \beta_{1}-\alpha_{1}\right)-(1-\pi) v\left(\beta_{2} x_{0}+\beta_{1} x_{1} / \dot{q}_{1}\right), \\
& F^{4}(\phi) \equiv \pi u\left(\beta_{1} x_{1}[1-\pi] / \beta_{2} \pi\right)+(1-\pi) \nabla\left(\beta_{1} x_{0} x_{1} /\left[x_{1}-a_{2}\right]+\beta_{2} x_{0} \pi /[1-\pi]\right) \\
& -\pi u\left([1-\pi]\left[x_{1}-\alpha_{2}\right] / \pi-\alpha_{1}\right)-(1-\pi) v\left(\beta_{2} x_{0} /[1-\pi]\right) \text {. }
\end{aligned}
$$


Given the equivalence between (35) and (45) and between (34) and (57), since $\theta>\theta$ and given the concavity of $u(\cdot)$ and $r(\cdot)$, we have $F^{2}(\phi)<F^{3}(\phi)$. Since $g_{1}<\bar{q}_{1}$, and given that $u(\cdot)$ and $\nabla(\cdot)$ are concave and $-c^{\prime \prime}(c) / u^{\prime}(c) \geq 1$; it follows that $F^{1}(\phi)<F^{2}(\phi)$. Finally, $F^{3}(\phi)<F^{4}(\phi)$ as $q_{1}<\dot{q}_{1}$ and $v(\cdot)$ and $\nabla(\cdot)$ are concave. We therefore have

$$
F^{1}(\phi)<F^{2}(\phi)<F^{3}(\phi)<F^{4}(\phi)
$$

From $(60)$, the sets $W(S), S=\{2\},\{8\},\{1,6\},\{1,2,6\},\{1,6,8\}$, are disjoint, and $\underset{S}{U} W(S)$ is the parameter space. Therefore, an equilibrium always exists, and it is unique, from Propositions 5-9.

It is straightforward to show that $W(S)$ is of positive measure for each $S, s 0$ that there exist parameters for which an equilibrium of each type exists. First, note that $F^{1}(\phi)>0$ for $\beta_{1}=\beta_{2}$, which implies that $W\{2\}$ is of positive measure, by continuity. Next, note that $\mathrm{F}^{4}(\phi)=0$ for $\alpha_{1}=\alpha_{2}=0$ and $\beta_{1}=\beta_{2}$. Now, $\delta F^{4} / \delta \beta_{2}<0$ when $\beta_{1}=$ $\beta_{2}$ so that, again by continuity, there exists a subset of the parameter space of positive measure where $F^{4}<0$, i.e. $W(\{8\})$ is of positive measure. Therefore, from $(60), W(S)$ is of positive measure for each $S$.

The parameter space can thus be divided into three regions of interest. First, there is a region where only the liquid asset is traded (equilibrium $\{2\}$ ); second, there is a region where only the illiquid asset is traded (equilibrium $\{8\}$ ); third, there exists a "diversification region," where both assets are acquired and traded in equilibrium (either $\{1,6\},\{1,2,6\}$, or $\{1,6,8\})$. The locus $F^{1}(\phi)=0$ separates the region in which the illiquid asset is traded from the region in which it is not. Here, $\partial F^{1} / \partial \alpha_{1}>0, \partial F^{1} / \partial \alpha_{2}>0$, and $\partial F^{1} / \partial \beta_{2}<0$. Similarly, the locus $F^{4}(\phi)$ separates the region in which the liquid asset is traded from the region where it is not. We have $\partial F^{4} / \partial \alpha_{1}>0, \partial F^{4} / \partial a_{2}>0$, and $\partial \mathrm{F}^{4} /\left.\partial \beta_{2}\right|_{F^{4}=0}<0$. Therefore, the illiquid asset will be "more likely" to be acquired and traded, and the liquid asset "less likely" to be acquired and traded, as transactions costs 
increase and the return on the illiquid ssset incresses. These results are quite intuitive.

\section{The Optimal Provision of Liquidity}

The objective of this section is to derive a welfare result to show how liquidity is underprovided in a competitive equilibrium, relative to a social optimum. In evaluating the optimality of the competitive equilibrium, we follow the spirit of work on incomplete markets (e.g. Geanakoplos and Polemarchakis 1986). Here, we allow the social planner to determine the fractions of agents holding liquid and illiquid assets in period 0 . We let $\gamma$ denote the fraction of agents initially holding the liquid asset, i.e. $\gamma=p_{1}+p_{2}$. The planner must respect the restriction on diversification, and agents are free to trade assets on competitive markets in period 1. Thus, the set of allocations that the planner can achieve are competitive equilibria, indexed by $\gamma \in[0,1]$. That is, a feasible allocation for the planner is a competitive equilibrium, satisfying $(17)-(20)$, but imposing the constraint

$$
p_{1}+p_{2}=\gamma, \gamma \in[0,1]
$$

In addition, (21) is replaced by

$$
\text { If } p_{j}>0 \text { and } \gamma>1 \text {, then } U_{j}\left(q_{1}, q_{2}\right) \geq U_{k}\left(q_{1}, q_{2}\right) ; j, k=1,2 \text {. }
$$

Here, (62) and (63) state that agents cannot choose their actions in period 0 , but their choices in period 1 must be optimal.

We define an allocation to be constrained Pareto optimal if there is no allocation which is feasible for the planner which makes all agents better off without making any worse off. Clearly, there exist parameter values for which the competitive equilibrium will be constrained Pareto optimal. First, if the return on the illiquid asset, 
$\beta_{2}$, is sufficiently large and transactions costs sufficiently smiall, then equilibrium $\{8\}$ with trade only in the illiquid asset, will be the competitive equilibrium. This competitive equilibrium could not be improved upon by forcing some agents to hold the liquid asset, provided the return on the liquid asset, $\beta_{1}$, is sufficiently small relative to $\beta_{2}$. Second, transactions costs can always be made sufficiently large that the competitive equilibrium is equilibrium $\{2\}$, where only the liquid asset is traded. If transactions costs are large enough to preclude trade in the illiquid asset, then forcing agents to hold the illiquid asset forces them to consume zero if they are early consumers. Thus, in this case the competitive equilibrium would be constrained Pareto optimal. The natural region of the parameter space to look for suboptimal equilibria is then somewhere near or in the region where both assets are traded.

Now, we will show that there are conditions under which suboptimal equilibria, with too little liquidity provision, exist near the locus $F^{1}(\phi)$. This locus defines a boundary between the regions where equilibrium $\{2\}$ exists, and where equilibrium $\{1,2,6\}$ does. Assume that

$$
u^{\prime}(x) \geq v^{\prime}(x) \text { for all } x>0 \text {, }
$$

and

$$
\pi \geq x_{1} /\left(\beta_{1} x_{0}+x_{1}\right)
$$

In the region defined by $F^{1}(\phi) \geq 0$, we have equilibrium $\{2\}$. The adjacent region of the parameter space is $W(\{1,2,6\})$, so that both regions have a positive fraction of agents making choice 2 , and expected utility is equal to $U_{2}\left(q_{1}, q_{2}\right)$. Note also that, from (26), (38), and (42)-(44), $q_{1}$ is a continuous function of the parameters at the locus $F^{1}(\phi)=0$ separating the regions $W(\{2\})$ and $W(\{1,2,6\})$. Differentiating expected utility with respect to $q_{1}$ and evaluating the derivative along $F^{1}(\phi)=0$, using $(10)$ and $(26)$ we get 


$$
\begin{aligned}
& \left.\left(d / d q_{1}\right)\right|_{q_{1}}=(1-\pi) x_{1} / \pi x_{0}\left[\pi\left(q_{1} x_{0}\right)+(1-\pi) \nabla\left(\beta_{1} x_{0}+\beta_{1} x_{1} / q_{1}\right)\right] \\
& =\left[\pi x_{0} /(1-\pi) x_{1}\right]\left\{(1-\pi) x_{1} u^{\prime}\left[(1-\pi) x_{1} / \pi\right]-\pi x_{0} \beta_{1} \nabla^{\prime}\left[\beta_{1} x_{0} /(1-\pi)\right]\right\} \\
& >\left[\pi x_{0} /(1-\pi) x_{1}\right]\left\{(1-\pi) x_{1} u^{\prime}\left[(1-\pi) x_{1} / \pi\right]-\pi x_{0} \beta_{1} \nabla^{\prime}\left(\beta_{1} x_{0}\right)\right\} \\
& =\left[\pi^{2} x_{0} /(1-\pi) x_{1}\right]\left\{\left[(1-\pi) x_{1} / \pi\right] u^{\prime}\left[(1-\pi) x_{1} / \pi\right]-x_{0} \beta_{1} \nabla^{\prime}\left(\beta_{1} x_{0}\right)\right\} \\
& \geq\left[x^{2} \beta_{1} x_{0}^{2} /(1-\pi) x_{1}\right]\left[u^{\prime}\left(\beta_{1} x_{0}\right)-\nabla^{\prime}\left(\beta_{1} x_{0}\right)\right] \geq 0 .
\end{aligned}
$$

Here, the second inequality follows from $-\mathrm{cu}^{\prime \prime}(\mathrm{c}) / \mathrm{u}^{\prime}(\mathrm{c}) \geq 1$ and (65), while the third inequality is implied by (64). Now, note from the proof of Proposition 8 in the Appendix, that $q_{1}<\bar{q}_{1}$ in equilibrium $\{1,2,6\}$, where, from (26) and (48), $\bar{q}_{1}$ is the price of the liquid asset in equilibrium \{2\}. Therefore, from the above, expected utility falls, given (64) and (65), when a parameter change canses the illiquid asset to be adopted. From the planner's point of view, equilibrium $\{2\}$ is still feasible in region $W(\{1,2,6\})$, by simply setting $\gamma=1$. Therefore, equilibrium $\{1,2,6\}$ is suboptimal, given (64) and (65), in a neighborhood of the boundary $F^{1}(\phi)=0$.

The above results state that, if liquidity matters enough, then expected utility falls when a parameter change causes the illiquid asset to be adopted. Liquidity matters sufficiently if the marginal utility of early consumption is sufficiently large relative to the marginal utility of late consumption $((64)$ holds) and if the probability of early consumption is sufficiently large ((65) holds). All agents would be better off if they continued to hold the liquid asset rather than having some trade in illiquid assets, and the competitive equilibrium is suboptimal. The underprovision of liquidity occurs here because of a participation externality. That is, as the number of agents participating in the market for the illiquid asset increases, this tends to drive down the price of the liquid 
asset. Moving from a region of the parameter space where equilibrium \{2\} exists to one where equilibrium $\{1,2 ; 6\}$ exists, $p_{1}$ incresses relative to $p_{2}$, and $q_{1}$ must fall, from (17). As a result of the decrease in its price, the liquid asset becomes less desirable, and the increase in participation in the market for the illiquid asset is self-fulfilling.

The negative participation externality which exists in this model contrasts with the positive externalities present in models constructed in Chatterjee (1988), Pagano (1989), and Allen and Gale (1991). Also, our model has a unique equilibrium, whereas these other models all feature multiple equilibria.

\section{Examples}

To illustrate possible equilibrium outcomes, some equilibria were computed numerically. Here we assume $u(c)=\ln (c), v(c)=\ln (c), \beta_{1}=x_{0}=x_{1}=1$, and $\alpha_{1}=\alpha_{2}=\alpha$. We thus constrain the two-period interest rate on the liquid asset to be zero, and the equilibria computed have $\beta_{2} \in(1,1.1)$, so that the two-period interest rate on the illiquid asset is at most $10 \%$. We used three different values for the probability of early consumption, $\pi=.1$, $\pi=.5$, and $\pi=.9$. For each value of $\pi$, equilibria were computed over a two-dimensional grid in $\left(\alpha, \beta_{2}\right)$ space.

In Figures $1-3$, for each value of $\pi$ the parameter space is subdivided into the regions where each type of equilibrium exists. Note here, that for a given value of $\beta_{2}$, equilibria with trade in the illiquid asset tend to be supported with higher transactions costs, the smaller is $\pi$. The illiquid asset is traded in equilibria $\{8\},\{1,6,8\},\{1,6\}$, and $\{1,2,6\}$. In Figure 1 , trade in the illiquid asset is supported with $\beta_{2}=1.05, \alpha=1.5$, and $\pi$ $=1$, i.e. there is trade in the illiquid asset with a cost of buying or selling this asset 1.5 times the endowment of late consumers in period 1. However, in Figure 3, with $\beta_{2}=1.05$, $\alpha=.006$, and $\pi=.9$, there is no trade in the illiquid asset. Also note, from Figures 1-3, that the larger is $\pi$ the smaller tends to be the range of transactions costs, for given $\beta_{2}$, over which both assets are acquired and traded (the region where equilibria $\{1,6,8\},\{1,6\}$, and $\{1,2,6\}$ exist). 
Figures 4, 6, and 8 are three-dimensional plots of expected utility computed over the same grids as for Figures 1, 2, and 3, respectively. Figures 5, 7, and 9 are cross sections of Figures 4, 6, and 8, respectively, with $\beta_{2}=1.05$. In Figures 4 and 5 , with $\pi=$ .1 , expected utility decreases monotonically for fixed $\beta_{2}$ as $\alpha$ increases. That is, higher transactions costs imply lower welfare. In contrast, with higher $\pi$ in Figures $6-\theta$, expected utility can rise as $\alpha$ increases. Note that, for $\pi=.9$, from Figures 3 and 9 , that with $\beta_{2}=$ 1.05 expected utility is lower through much of the region where equilibrium $\{8\}$ exists (only the illiquid asset is traded) than in the region where equilibrium $\{2\}$ exists (only the liquid asset is traded). Figures 7, 10, and 11 illustrate why expected utility can fall when transactions costs decrease. Regions where this happens are also regions where the fraction of agents acquiring the liquid asset $(\gamma)$ and asset prices decrease dramatically. Thus, as transactions costs fall, participation in the market for the illiquid (liquid) asset rises (falls), in such a way that the price of the liquid asset falls and agents are worse off.

In Figures 12-18, expected utility is computed for equilibria where a social planner constrains the fraction of agents holding each asset at the initial date. Here, $\gamma$ is the fraction of agents holding the liquid asset, $u 1$ is the expected utility of those agents, and $\mathrm{u}_{2}$ is the expected utility of agents holding the illiquid asset. In Figure 12, the competitive equilibrium is where $\mathrm{u} 1$ and $\mathrm{u} 2$ intersect near $\gamma=.1$, and this is constrained Pareto optimal. Similarly, in Figure 13, the competitive equilibrium is at $\gamma=1$, and it is constrained Pareto optimal. No suboptimal equilibria were found for $\pi=.1$.

Now, consider Figure 14. Here, the competitive equilibrium is at $\gamma=0$, but all agents are better off if $\gamma=1,80$ the competitive equilibrium is suboptimal. In Figure 15, the competitive equilibrium is located where $u 1$ intersects $u 2$, and again this is suboptimal, being dominated by $\gamma=1$. In Figure 16, the competitive equilibrium is $\gamma=$ 1, which is constrained Pareto optimal. In Figures 14-16, there is in general too little liquidity in a competitive equilibrium, and $\gamma=1$, though a constrained Pareto optimum, is not a unique constrained Pareto optimum. Similarly, with $\pi=.9$ in Figure $17, \gamma=0$ is the competitive equilibrium, which is suboptimal, as it is dominated by $\gamma=1$, but there 
is a continuum of constrained Pareto optima. In Figures 18 and 19, however, $\gamma=1$ is the unique constrained Pareto optimum. In Figure 18, $\gamma=1$ dominates the competitive equilibrium, where $\mathrm{n} 1$ and $\mathrm{u} 2$ intersect, and in Figure $19, \gamma=1$ is also the competitive equilibrium.

These examples illustrate a tendency for a higher probability of a need for liquidity (higher $\pi$ ) to produce suboptimality with greater likelihood. There was never too much liquidity provided; all competitive equilibria were either constrained Pareto optimal or dominated by feasible allocations where more liquid assets were held.

\section{Conclusion}

We have constructed a model of asset market participation where there is a tendency for underprovision of liquidity. In this sense, our model differs from related models of market participation, for example Chatterjee (1988), Pagano (1989), and Allen and Gale (1891), where multiple equilibria arising from a participation externality can lead to the overprovision of liquidity. In our model, there can be too little liquidity, or too much participation in the market for the illiquid asset, as the price of the liquid asset tends to fall when participation in this market increases. A decrease in the liquid asset's price tends to make liquid asset holders worse off, and the increase in participation in the market for the illiquid asset is self-fulfilling. However, the competitive equilibrium for this economy is unique.

This is a useful model of multiple asset markets, permitting the volume of trade on each market to be determined endogenously, with possible outcomes involving trade in both assets, trade in only the liquid asset, or trade in both assets. Given the nonconvexities in individual agents' optimization problems due to fixed transactions costs and the constraint that agents cannot diversify their portfolios, different agents may participate in different markets and make different portfolio decisions. This occurs in spite of the fact that agents are identical, ex ante.

One possible extension of the model would be to introduce some aggregate 
uncertainty by making the fraction of early consumers random as of period 0 . As a result, the prices of the liquid and illiquid assets would also be random. This could possibly create participation externalities of the type studied by Chatterjee (1988), Pagano (1989), and Allen and Gale (1991), and might provide an interesting interaction with the externality already present here. Another extension could involve embedding the model in an overlapping generations framework in which the liquid asset was fiat currency wed for intergenerational trade. Here, government monetary interventions affecting rates of return would change the degree of market participation (see Chatterjee and Corbae 1991). It might be expected that some modification to the standard welfare results for overlapping generations models would result. 


\section{Appendix}

\section{Proof of Proposition 5}

Given $p_{2}=1$ and $p_{j}=0$ for all $j \neq 2$, and (26), (17)-(20) are satisfied by construction, except for $q_{2} \geq 0$. For an equilibrium, we must find a price for the illiquid asset, $q_{2} \geq 0$, such that (21) is satisfied for $j=2$ and $k \neq 2$, given (26). With $j=2$ and $k=1$ in (21), and substituting using (26), we get

$$
\beta_{1} x_{0} /(1-\pi) \geq\left(\beta_{2} / q_{2}\right)\left(x_{1} / \pi-\alpha_{2}\right)
$$

Similarly, inequality (21) with $j=2$ and $k=6$ gives

$$
\begin{aligned}
\pi\left([1-\pi] x_{1} / \pi\right)+(1-\pi) v\left(\beta_{1} x_{0} /[1-\pi]\right) & \geq \pi\left(q_{2} x_{0}-\alpha_{1}\right) \\
& +(1-\pi) v\left(\beta_{2} x_{0}+\beta_{1} \pi x_{0} /[1-\pi]\right) .
\end{aligned}
$$

Inequalities (A.1) and (A.2) imply lower and upper bounds, respectively, that $q_{2}$ must satisfy in equilibrium. If (A.1) holds, then

$$
\begin{aligned}
U_{8}\left(q_{1}, q_{2}\right) & \leq \pi u\left([1-\pi] x_{1} / \pi\right)+(1-\pi) v\left(\beta_{1} x_{0} /[1-\pi]\right)-(1-\pi) v\left(\beta_{2} x_{0}+\beta_{1} x_{0} \pi /[1-\pi]\right) \\
& +(1-x) v\left(\beta_{2} x_{0}+\beta_{1} x_{0} \pi\left[x_{1}-\alpha_{2}\right] /[1-\pi]\left[x_{1}-\pi a_{2}\right]\right) .
\end{aligned}
$$

Then, if (A.1) holds, we have $U_{8}\left(q_{1}, q_{2}\right)<U_{2}\left(q_{1}, q_{2}\right)$. Next, we need to show that (21) holds for $j=2$ and $k=7$. If (A.1) holds with equality, then

$$
\begin{aligned}
U_{6}\left(q_{1}, q_{2}\right)-U_{7}\left(q_{1}, q_{2}\right) & =(1-\pi) r\left(\beta_{2} x_{0}+\beta_{1} \pi x_{0} /\left[(1-\pi) x_{1}\right]\right) \\
& -(1-\pi) r\left(\beta_{2}\left(x_{1}-\pi a_{2}\right) x_{0} / x_{1}+\beta_{1} \pi x_{0} /(1-\pi)-\beta_{1} \pi x_{0} a_{1} /\left[(1-\pi) x_{1}\right]\right) \\
& >0 .
\end{aligned}
$$

In addition, (21) holds for $j=2$ and $k=3,4,5$, since $u^{\prime}(0)=0$. Therefore, equilibrium $\{2\}$ exists if and only if there is a $q_{2}>0$ satisfying (A.1) and (A.2). Since (A.1) defines a 
lower bound on $q_{2}$, and (A.2) an upper bound on $q_{2}$, we can take (A.1) as an equality, solve for $q_{2}$, and subotitute in (A.2). Then, equilibrium \{2\} exists if and only if (27) holds. If equilibrium \{2\} exists, it is essentially unique, which is trivial by construction, and from (26). Q.E.D.

\section{Proof of Proposition 6}

Inequality (21) must be satisfied for $j=8$ and $k=1$, or, using (28),

$$
\begin{aligned}
& \pi u\left(q_{1} x_{0}\right)+(1-\pi) v\left(\beta_{2} x_{0}^{2} \pi q_{1} /[1-\pi]\left[x_{1}-\alpha_{2}\right]+\beta_{2} \pi x_{0} /[1-\pi]\right) \\
& \leq \pi u\left([1-\pi]\left[x_{1}-\alpha_{2}\right] / \pi-\alpha_{1}\right)+(1-\pi) v\left(\beta_{2} x_{0} /[1-\pi]\right)
\end{aligned}
$$

Similarly, (21) must bold for $j=8$ and $k=6$, or

$$
\beta_{1} x_{1} / q_{1} \leq \beta_{2} x_{0} \pi /(1-\pi)
$$

Inequalities (A.4) and (A.5) put upper and lower bounds, respectively, on $q_{1}$. From (10), if (A.4) holds, and (A.5) holds with equality, then

$$
\begin{aligned}
U_{2}\left(q_{1}, q_{2}\right) & \leq U_{8}\left(q_{1}, q_{2}\right)-(1-\pi) v\left(\beta_{1} x_{0} x_{1} /\left[x_{1}-\alpha_{2}\right]+\beta_{2} \pi x_{0} /[1-\pi]\right) \\
& +(1-\pi) v\left(\beta_{1} x_{0}+\beta_{2} x_{0} \pi /[1-\pi]\right) \\
& <U_{8}\left(q_{1}, q_{2}\right)
\end{aligned}
$$

80 that (21) holds for $j=8$ and $k=2$. If (A.5) holds with equality, then using (14) and (15),

$$
U_{6}\left(q_{1}, q_{2}\right)-U_{7}\left(q_{1}, q_{2}\right)=\beta_{2} x_{0}-\beta_{2} x_{0}\left(x_{1}-a_{2}\right) / x_{1}+\alpha_{1} \beta_{2} \pi x_{0} /(1-\pi) x_{1}>0 .
$$

Thus, if (A.4) and (A.5) hold, then there exists a $q_{1}$ satisfying (A.4) and (A.5) which 
guarantees that (21) holds for $j=8$ and $k=7$. Aleo, (21) holds for $j=8$ and $k=3,4,5$, given (A.4). Therefore, in a manner similar to the proof of Proposition 5, equilibrium \{8\} exists if and only if there exists \& $q_{1} \geq 0$ satisfying (A.4) and (A.5), that is, taking (A.5) with equality and substituting in (A.4), we get (29). By construction, and from (28), it is trivial that equilibrium \{8\} is essentially unique if it exists. Q.E.D.

\section{Proof of Proposition 7}

Inequality (21) must hold for $j=1$ and $k=2$, that is, using (9), (10), (35), and (36),

$$
\beta_{2} \pi\left(p_{6} / p_{1}\right) /(1-\pi) \geq \beta_{1}+\beta_{1} /(1-\pi)\left(p_{6} / p_{1}\right)
$$

Also, (21) must hold for $j=6$ and $k=8$. Using (14), (16), (30), and (31), we get

$$
\beta_{1}\left(x_{1}-a_{2}\right) / \pi\left(p_{6} / p_{1}\right)^{2}+\beta_{1}(1-\pi) x_{1} / \pi\left(p_{6} / p_{1}\right) \geq \beta_{2}\left(x_{1}-a_{2}\right)
$$

Now, if (21) holds for $j=1$ and $k=2$, from (9) and (10) we have $\beta_{2} / q_{2}-\beta_{1} / q_{1}>0$, which implies that, from (14) and (15), (21) holds for $j=6$ and $k=8$. Inequality (21) holds for $j=1,6$ and $k=3,4,5$, as (30) implies that $q_{1}>0$ so that choice 1 dominates choices 3, 4, and 5, and choice 1 is in turn dominated by choice 2.

Let $\theta \equiv \mathrm{p}_{6} / \mathrm{p}_{1}$. Then, since the left side of (32) is increasing in $\theta$ and the right side is decreasing in $\theta$, and given the restrictions on $\mathrm{u}(\cdot)$ and $\mathrm{v}(\cdot)$, equation (32) yields a unique solution for $\theta$, which in turn gives unique solutions for $q_{1}, q_{2}, p_{1}$, and $p_{6}$ from (30), (31), and (33), and the solutions satisfy (20). We then have a unique equilibrium of type $\{1,6\}$ if the solution to (32), denoted by $\theta^{*}$, satisfies (A.6) and (A.7). Using (A.6), (A.7), we then get $\theta^{*} \geq Q$, and $\theta^{*} \leq \bar{\theta}$. Then, from (32), a unique equilibrium of type $\{1,6\}$ exists if and only if (34) and (35) hold. Q.E.D. 


\section{Proof of Proposition 8}

As (21) holds for $j=1$ and $k=2$, we have $\beta_{2} / q_{2}>\beta_{1} / q_{1}$, which implies that (21) holds for $j=6$ and $k=7$. In addition, (38) implies that $q_{1}>0$, and (21) holds for $j=2$ and $k$ $=3,4,5$.

For a solution to equation (41) to exist, denoted $q_{1}^{*}$, it is necessary and sufficient (by inspection) that

(A.8) $\quad \beta_{2}>\beta_{1}$.

Given (A.8), the right side of (41) is increasing in $q_{1}$ since $v(\cdot)$ is concave. Also, given (A.8), the left side of (41) is decreasing in $q_{1}$ for $q_{1}=q_{1}^{*}$, given that $u(\cdot)$ is concave and $-c u^{\prime \prime}(c) / u^{\prime}(c) \geq 1$. Thus, given (A.8), $q_{1}^{*}$ is unique. Given $q_{1}^{*},(40)$ and (42)-(44) solve uniquely for $q_{2}, p_{1}, p_{2}$, and $p_{6}$. We need to check that $p_{1}>0, p_{2}>0$, and $p_{6}>0$. From (42)-(44), these conditions are satisfied if and only if $q_{1}^{*}>q_{1}$ and $q_{1}^{*}<\bar{q}_{1}$. Therefore, from (41), a unique equilibrium exists if and only if (45) and (46) hold. Q.E.D.

\section{Proof of Proposition 9}

Given (51), we have

$$
\begin{aligned}
U_{2}\left(q_{1}, q_{2}\right) & =U_{6}\left(q_{1}, q_{2}\right)-(1-\pi) v\left(\beta_{1} x_{1} x_{0} /\left[x_{1}-a_{2}\right]+\beta_{1} x_{1} / q_{1}\right) \\
& +(1-\pi) v\left(\beta_{1} x_{0}+\beta_{1} x_{1} / q_{1}\right) \\
& <U_{6}\left(q_{1}, q_{2}\right)
\end{aligned}
$$

and (21) holds for $j=6$ and $k=2$. Since (21) then holds for $j=1$ and $k=2$, we then have $\beta_{2} / q_{2}>\beta_{1} / q_{1}$, which implies, from (14) and (15), that (21) holds for $j=6$ and $k=$ 7. In addition, (49) implies that $q_{1}>0$ so that, from (9), inequality (21) is satisfied for $j$ $=1$ and $k=3,4,5$.

Note that a necessary and sufficient condition for a solution to (52) is 


\section{(A.9) $\quad \beta_{2}\left(x_{1}-\alpha_{2}\right) / \beta_{1} x_{1}>1$.}

Given (A.9), the concavity of $\mathrm{u}(\cdot)$ and $\mathrm{v}(\cdot)$ imply that the left side of (52) is decreasing in $q_{1}$ and the right side of (52) is increasing in $q_{1}$. Therefore, if and only if (A.9) holds, a unique solution exists to (52), which we will denote $q_{1}^{* *}$. Given $q_{1}^{* *}$, we can solve uniquely for $q_{2}, p_{1}, p_{6}, p_{8}$, from (51), and (53)-(55). For this solution to be an equilibrium, we must have $p_{1}>0, p_{6}>0$, and $p_{1}+p_{6}<1$ or, using (53)-(55)), $q_{1}^{* *}>q_{1}$, and $q_{1}^{* *}<\dot{q_{1}}$. Therefore, substituting in (52), a unique equilibrium of type $\{1,6,8\}$ exists if and only if (56) and (57) hold. Q.E.D. 


\section{Pootnotes}

1. See Allen and Gale (1991) for references to the empirical evidence on limited diversification.

2. If there were a sufficiently large fixed cost (identical for each investment technology) associated with investment, then agents would not diversify. Also, insurance against the need for liquidity could be precluded by physically separating agents in period 0 .

3. To do this, collapse periods 0 and 1 into the first period of each agent's life. If an agent invests in the liquid asset, she buys fiat money at the beginning of the first period of life from the old of the previous generation. Asset trading takes place between young early consumers and young late consumers at the end of each period, after the current old die. 


\section{Reference}

Allen, F. and Gale, D. 1991. "Limited Market Participation and Volatility of Asset Prices," manuscript, University of Pennsylvania and Boston University.

Chatterjee, S. 1988. "Participation Externality as a Source of Coordination Failure in a Competitive Model with Centralised Markets," manuscript, University of Iowa. . and Corbae, D. 1991. "Endogenous Market Participation and the

General Equilibrium Value of Money, manuscript, University of Iowa.

Diamond, D. and Dybrig, P. 1983. "Bank Runs, Deposit Insurance, and Liquidity," Journal of Political Economy 91, 401-19.

Geanakoplos, J. and Polemarchakis, H. 1986. "Existence, Regularity, and Constrained Suboptimality of Competitive Portfolio Allocations When the Asset Market is Incomplete," in W.P. Heller and D.A. Starrett, eds. Uncertainty and

Communication. Esears in Honor of Kenneth J. Arrow, Vol. III, Cambridge University Press, Cambridge, MA.

Hart, O. 1975. "On the Optimality of Equilibrium When the Market Structure is Incomplete," Journal of Economic Theory 11, 418-43.

Pagano, M. 1988. "Endogenous Market Thinness and Stock Price Volatility," Review of Economic Studies 56, 269-288.

Wallace, N. 1988. "Another Attempt to Explain an Mliquid Banking System: the Diamond and Dybrig Model With Sequential Service Taken Seriously," Federal Reserve Bank of Minneapolis Quarterly Review 12, 3-16.

Woodford, M. 1990. "The Optimum Quantity of Money," in Friedman, B. and Hahn, F. eds. Handbook of Monetary Economics, North Holland, New York. 
Figure 1: Equilibrin, $P I=.1$

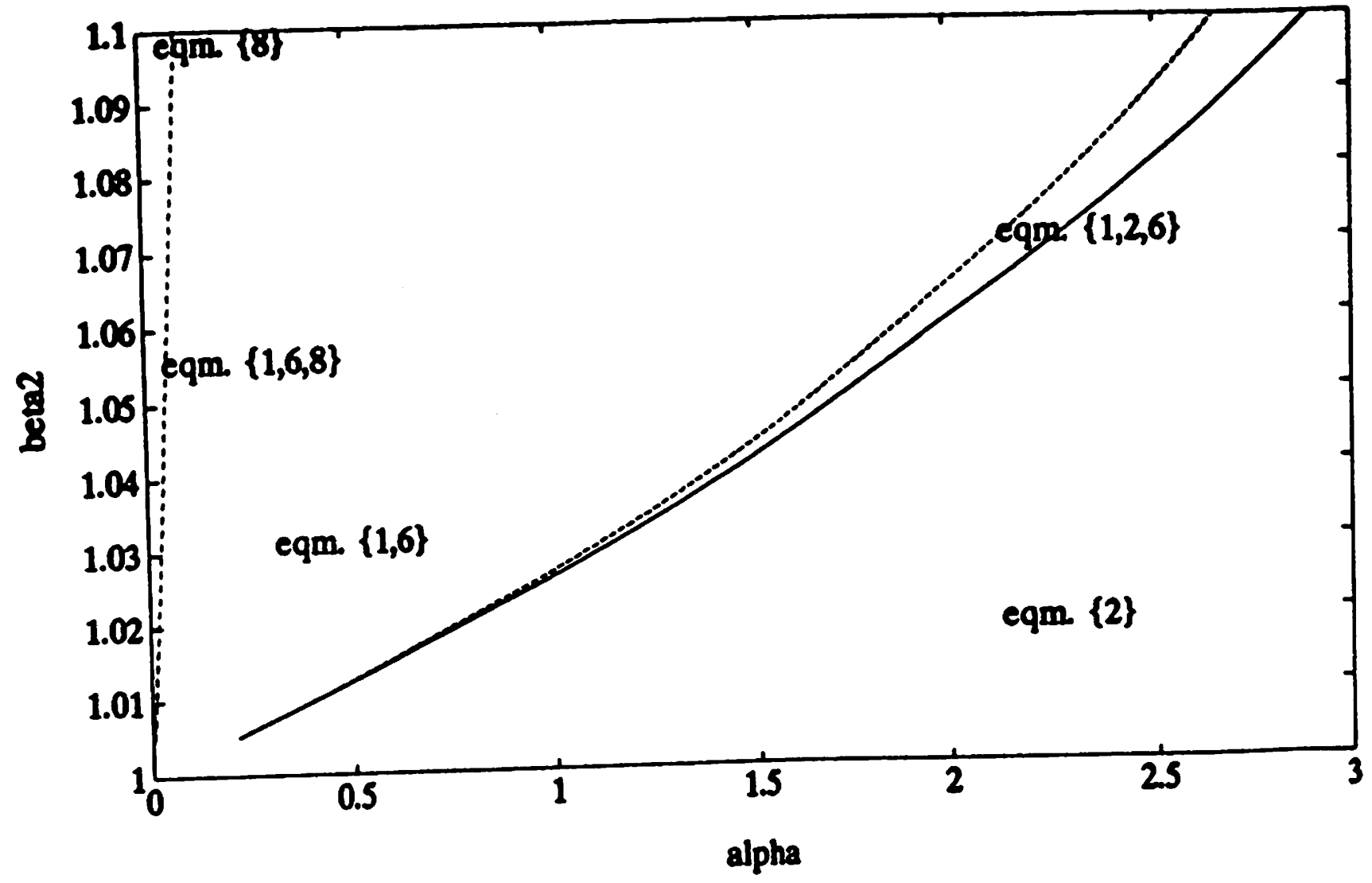

Figure 2: Equilibria, $\mathrm{PI}=.5$

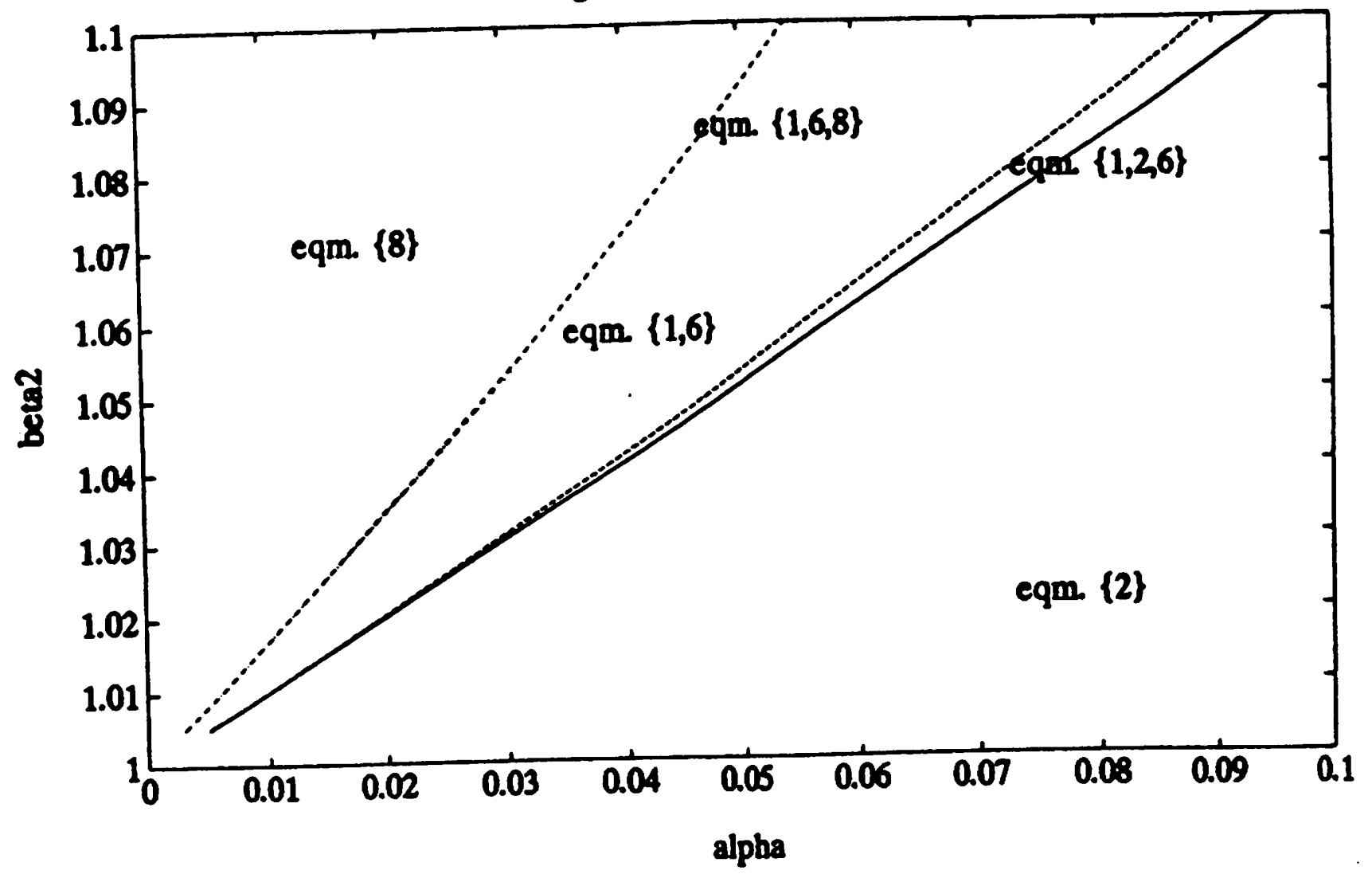


Figure 3: Equilibria, PI=.9

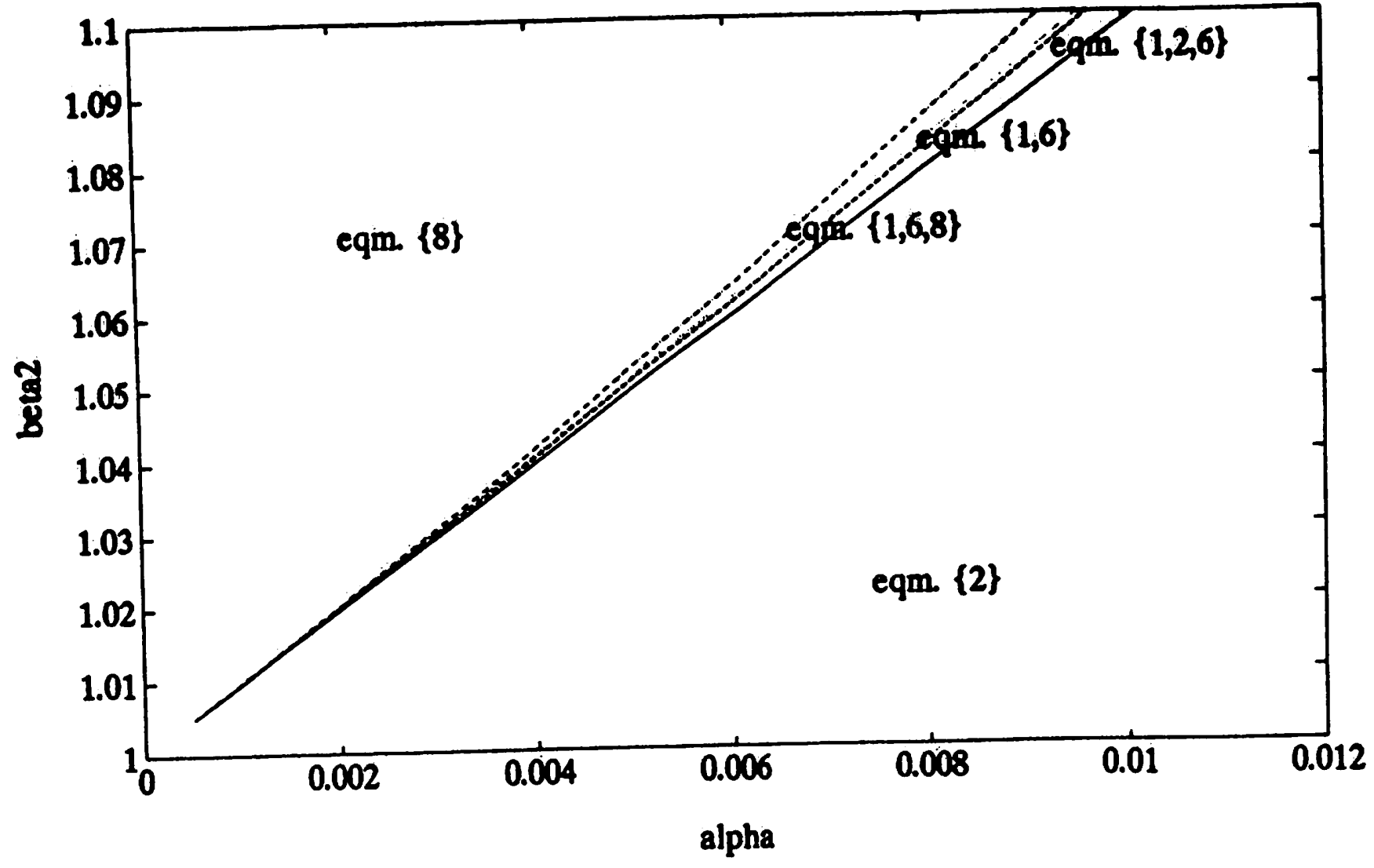


Figure 4: Expected Utility, PI=.1

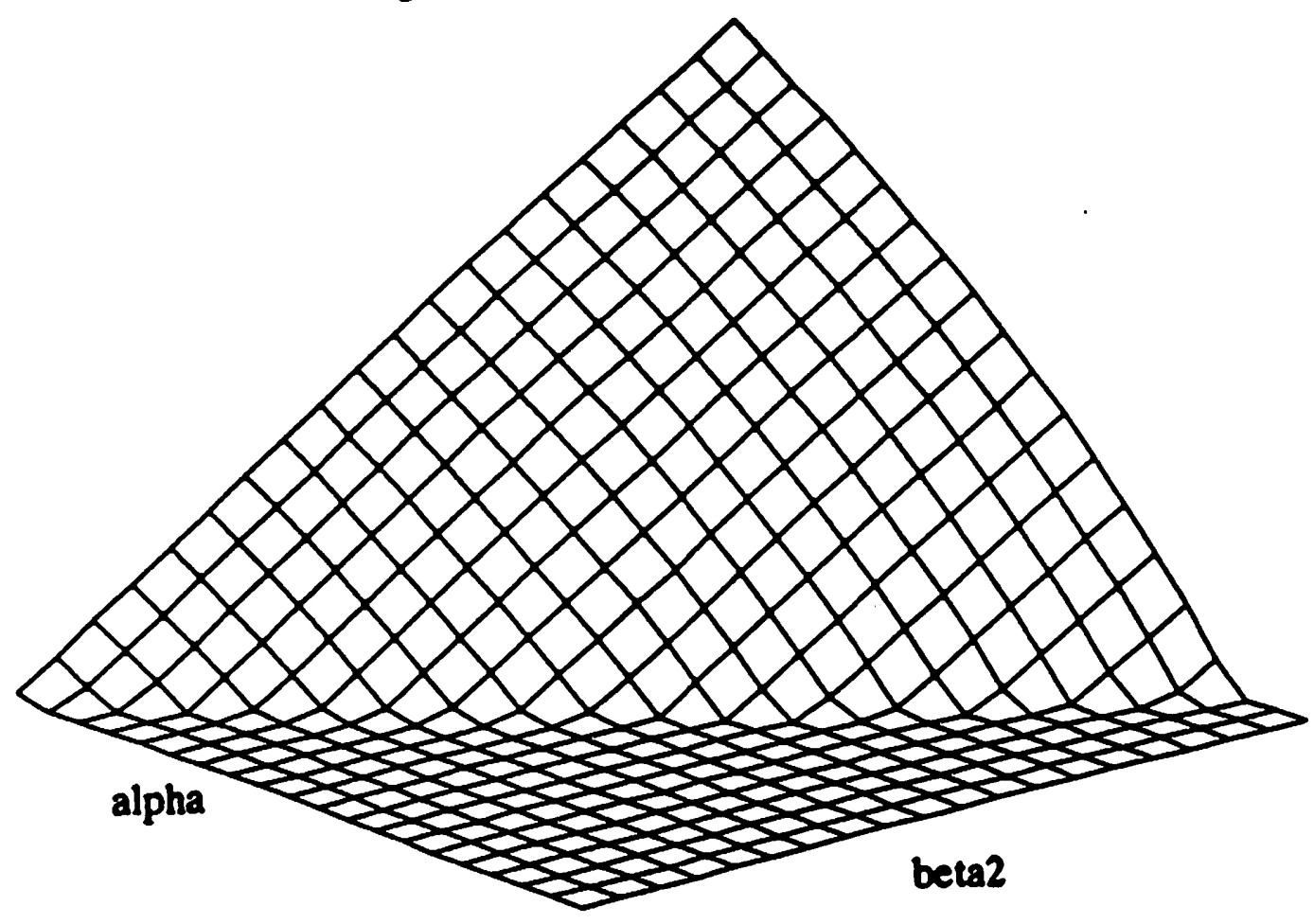

(alpha increasing SE; beta2 increasing NW)

Figure S: $p i=.1$, bets2 $=1.05$

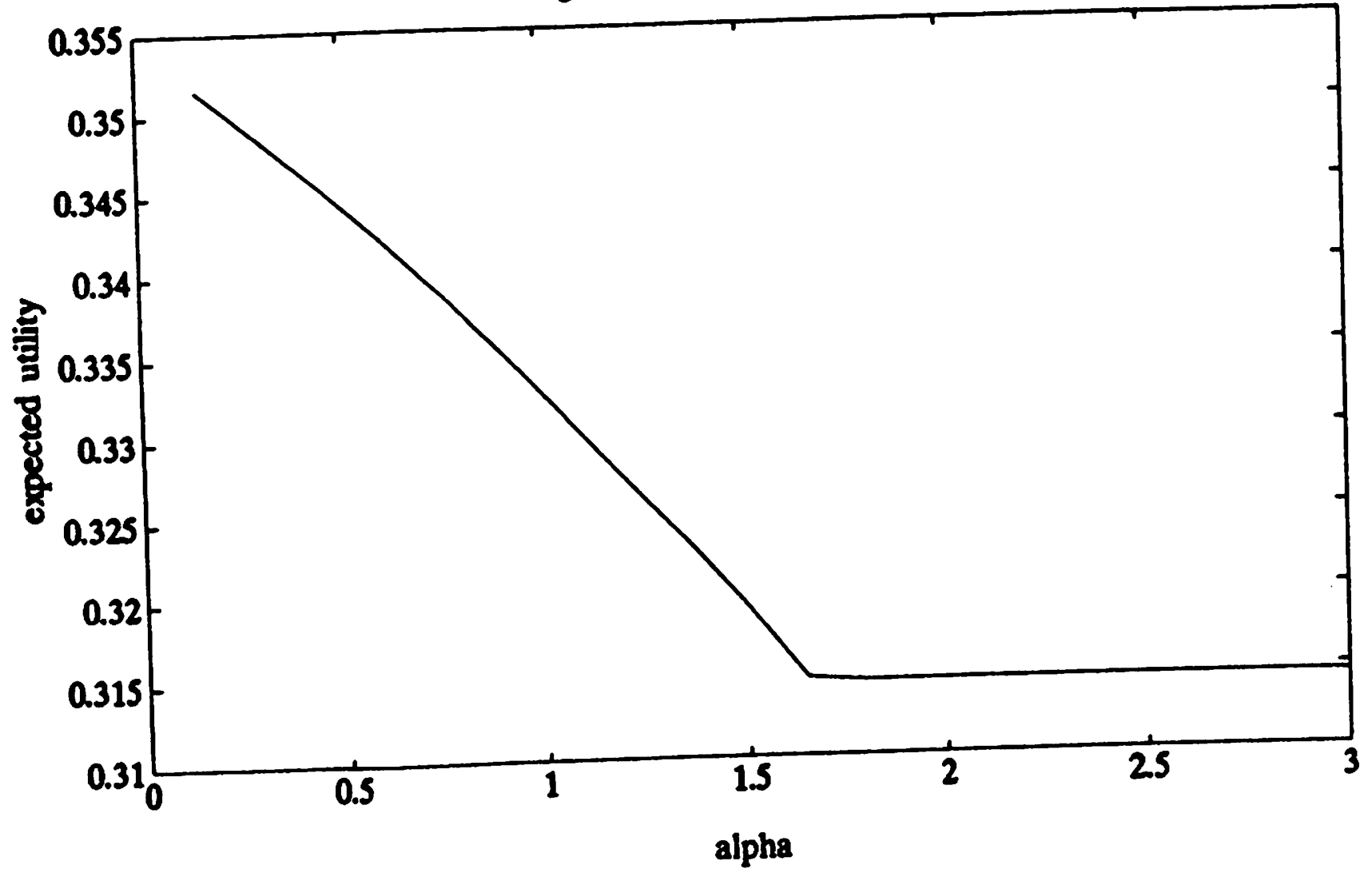


Figure 6. Expected Utility, PI=.S

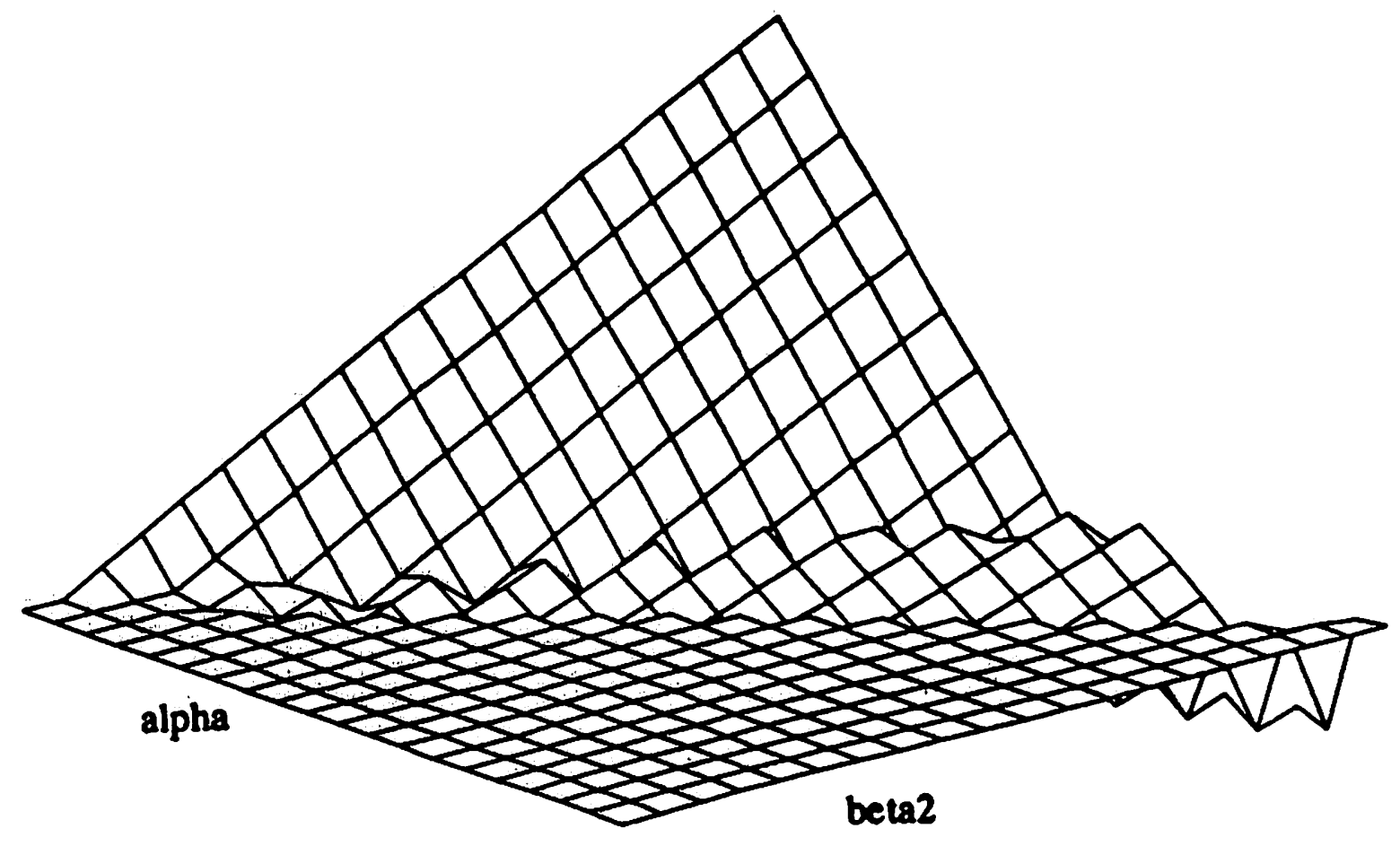

(alpha increasing $S E_{;}$beta2 increasing $N W$ )

Figure 7: $p i=5$, beta2 $=1.05$

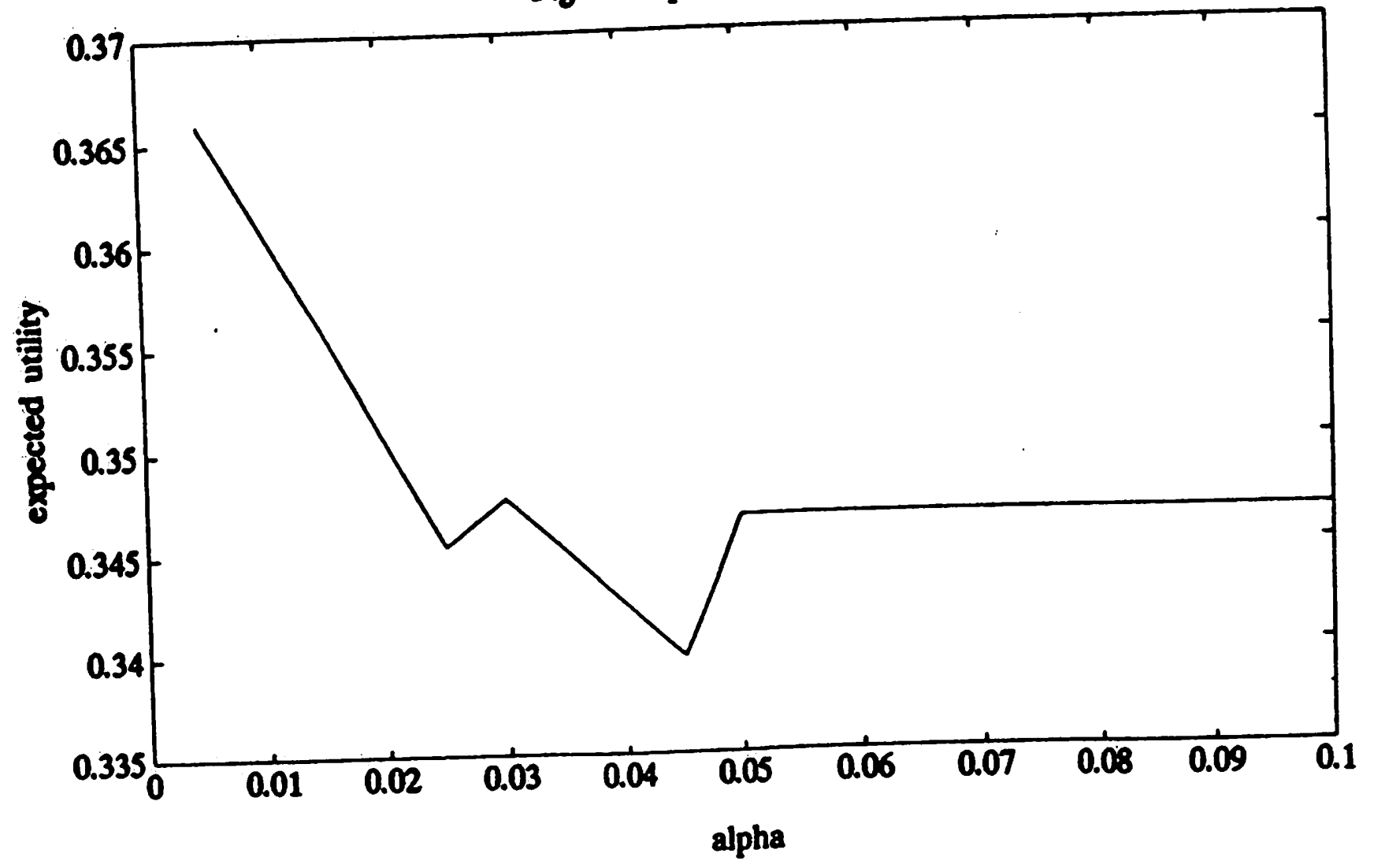




\section{Figure 8: Expected Utility, PI=.9}

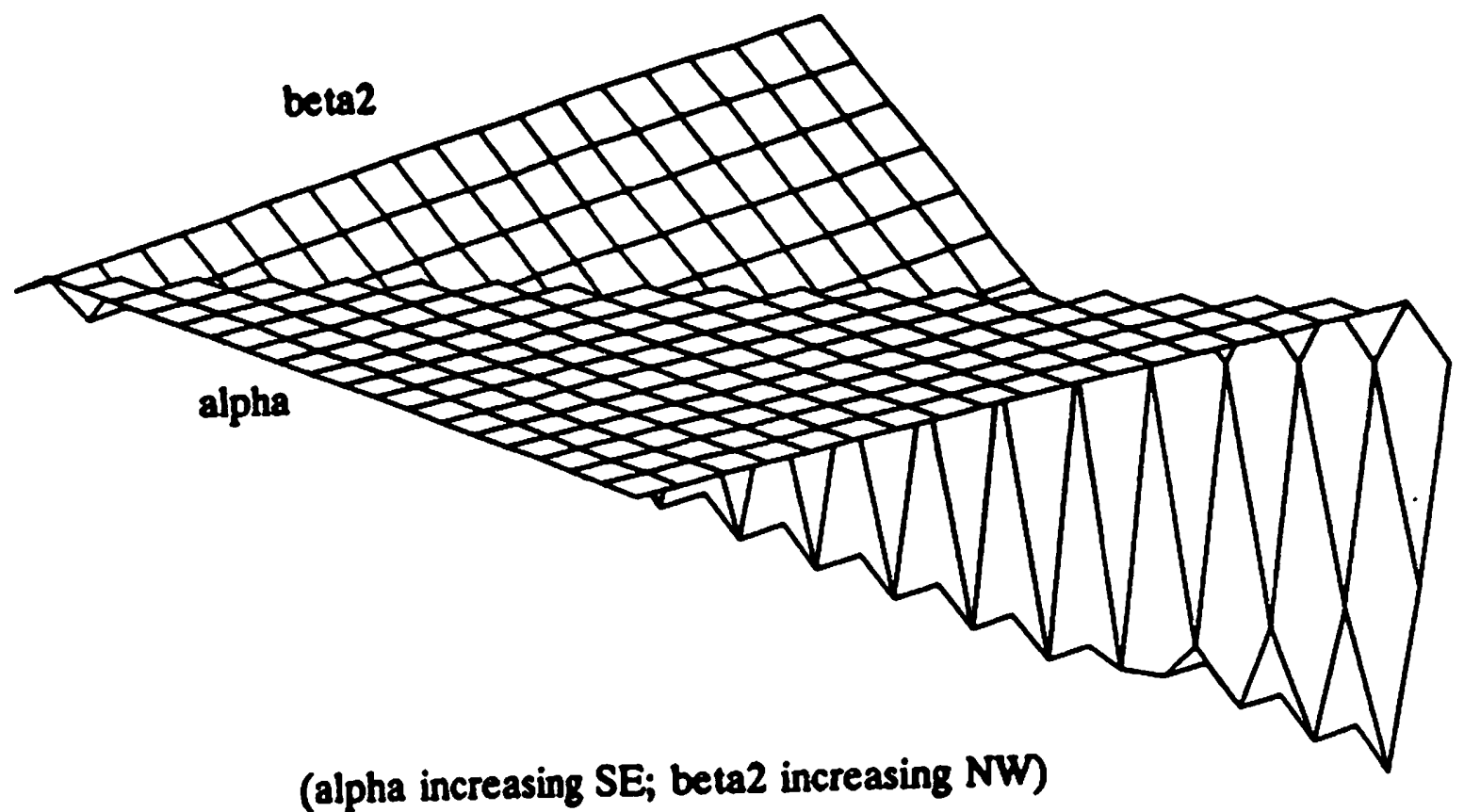

Figure 9: $p i=.9$, beta2 $=1.05$

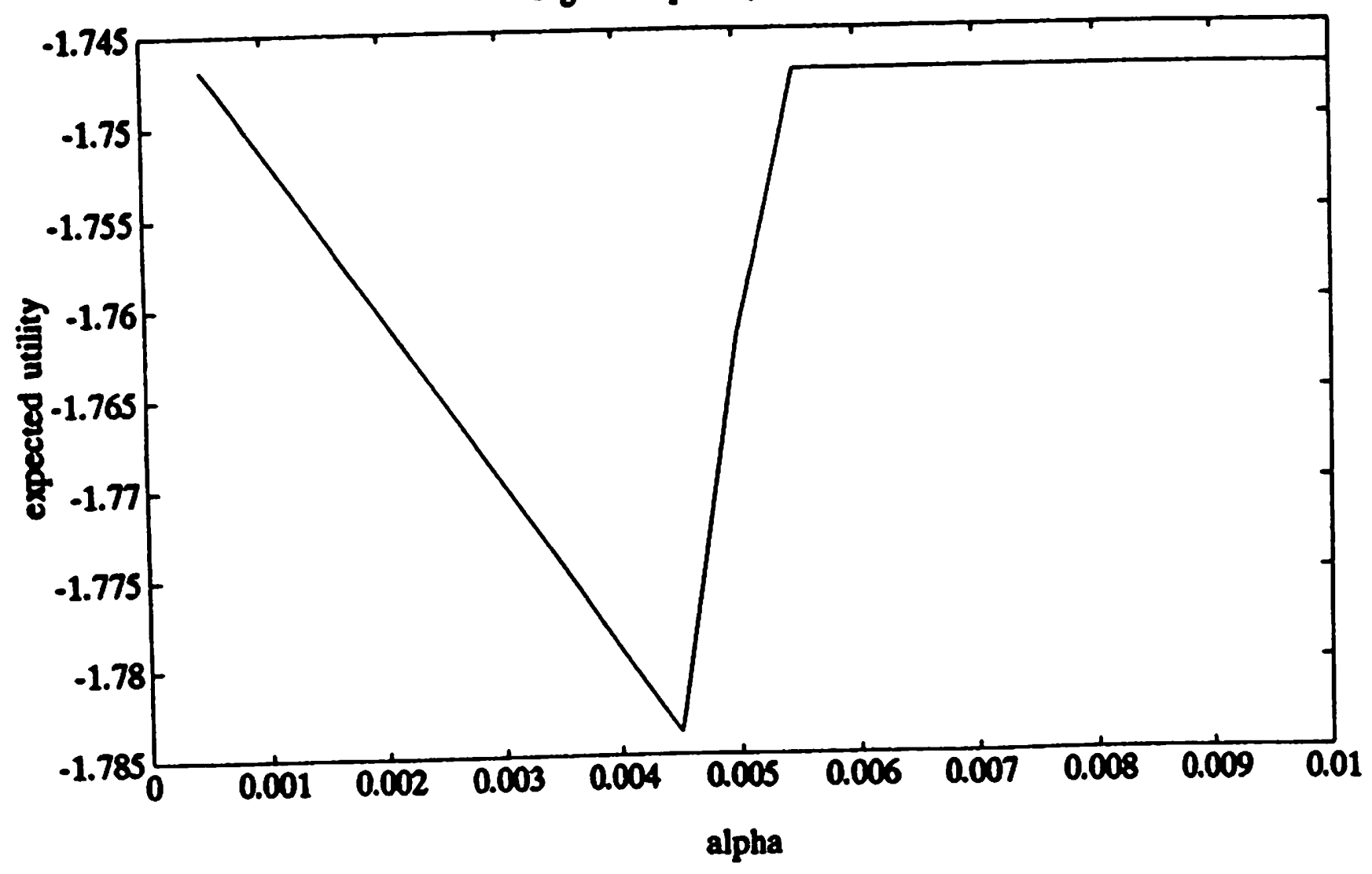


Figure 10: $p i=5$, beta2 $=1.06$

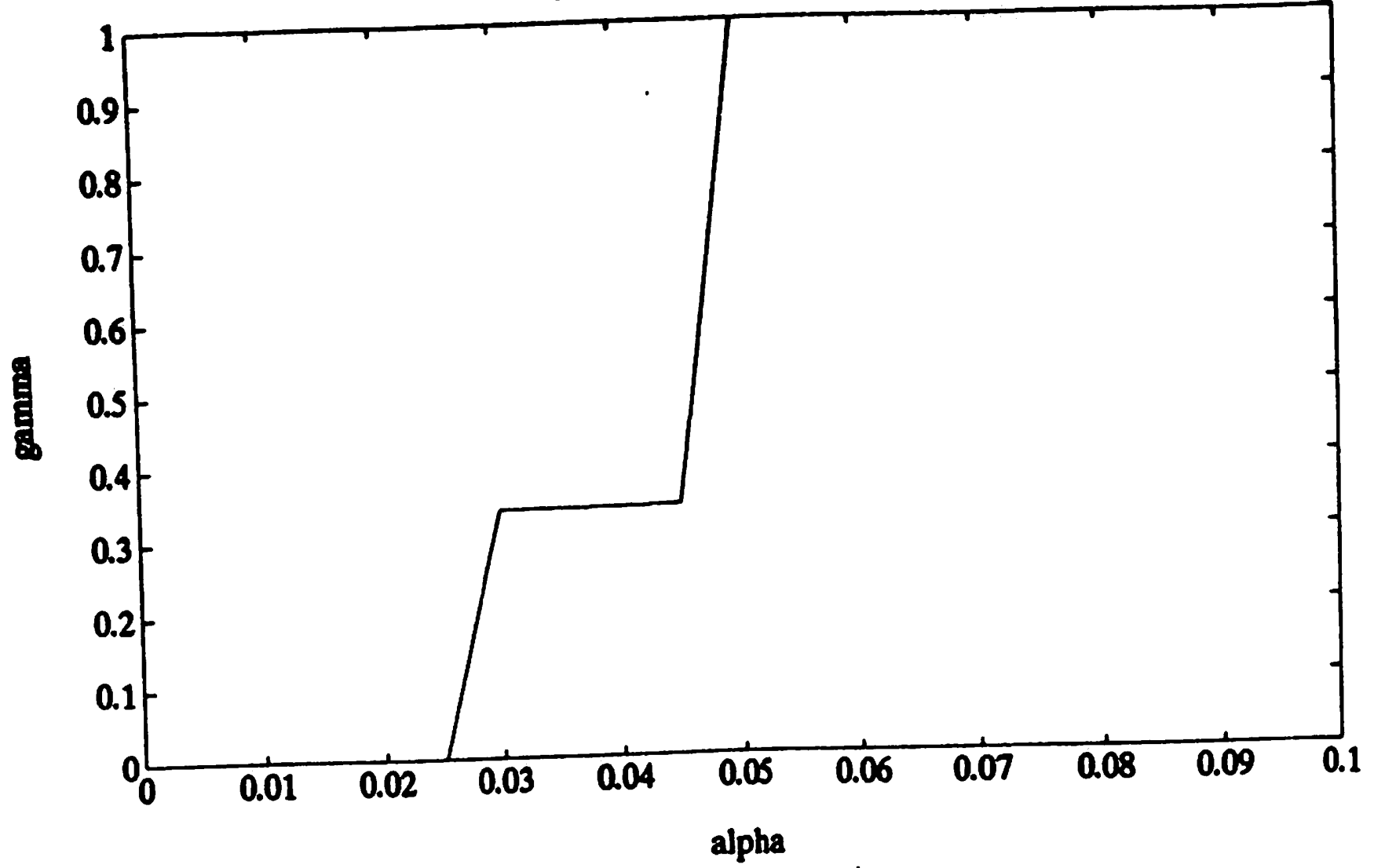

Figure 11: $p i=.5$, beta2 $=1.05$

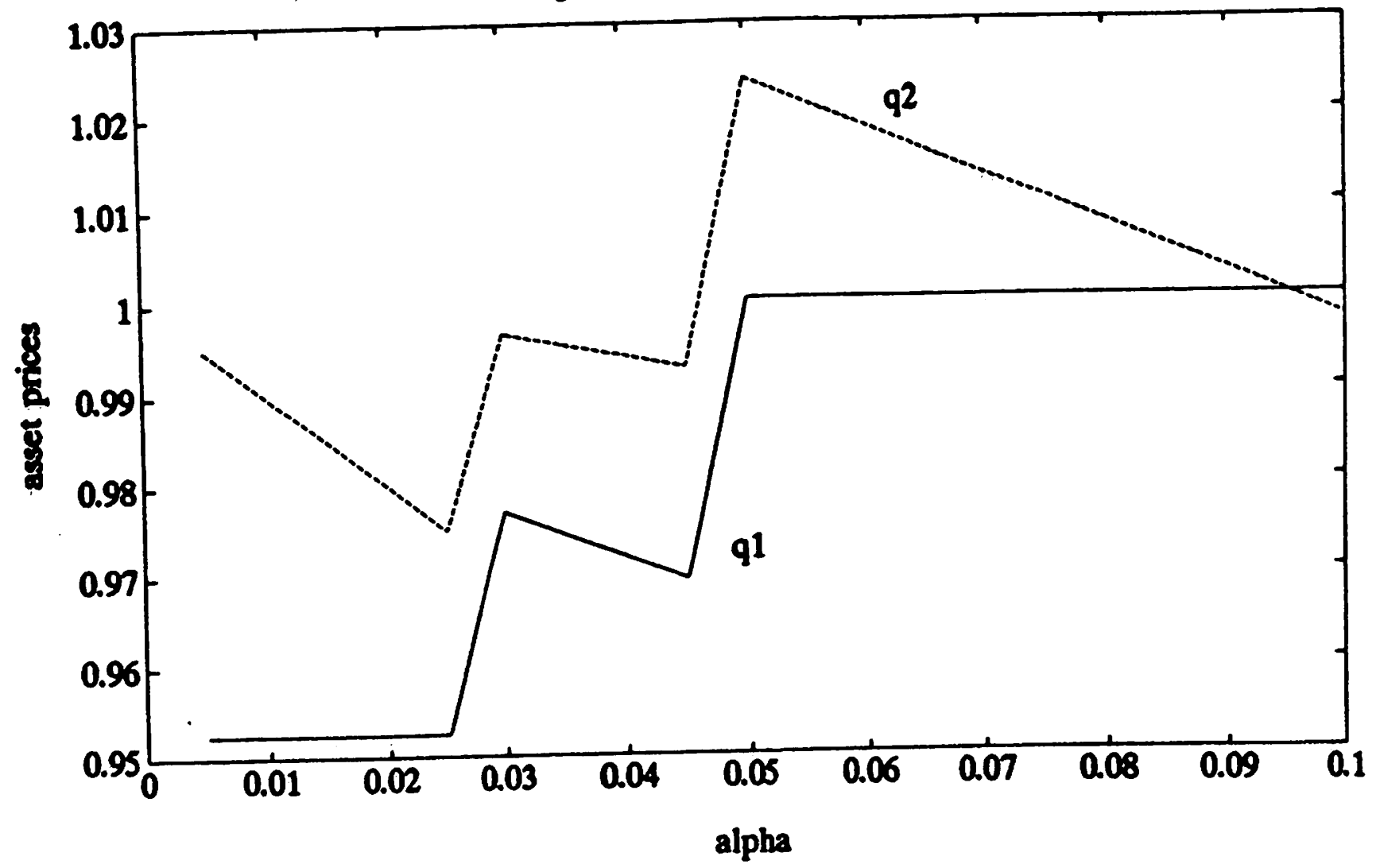


Figure 12: Constrained Equilibria, pi $=1$, beta2 $=1.05$, alpha $=.15$

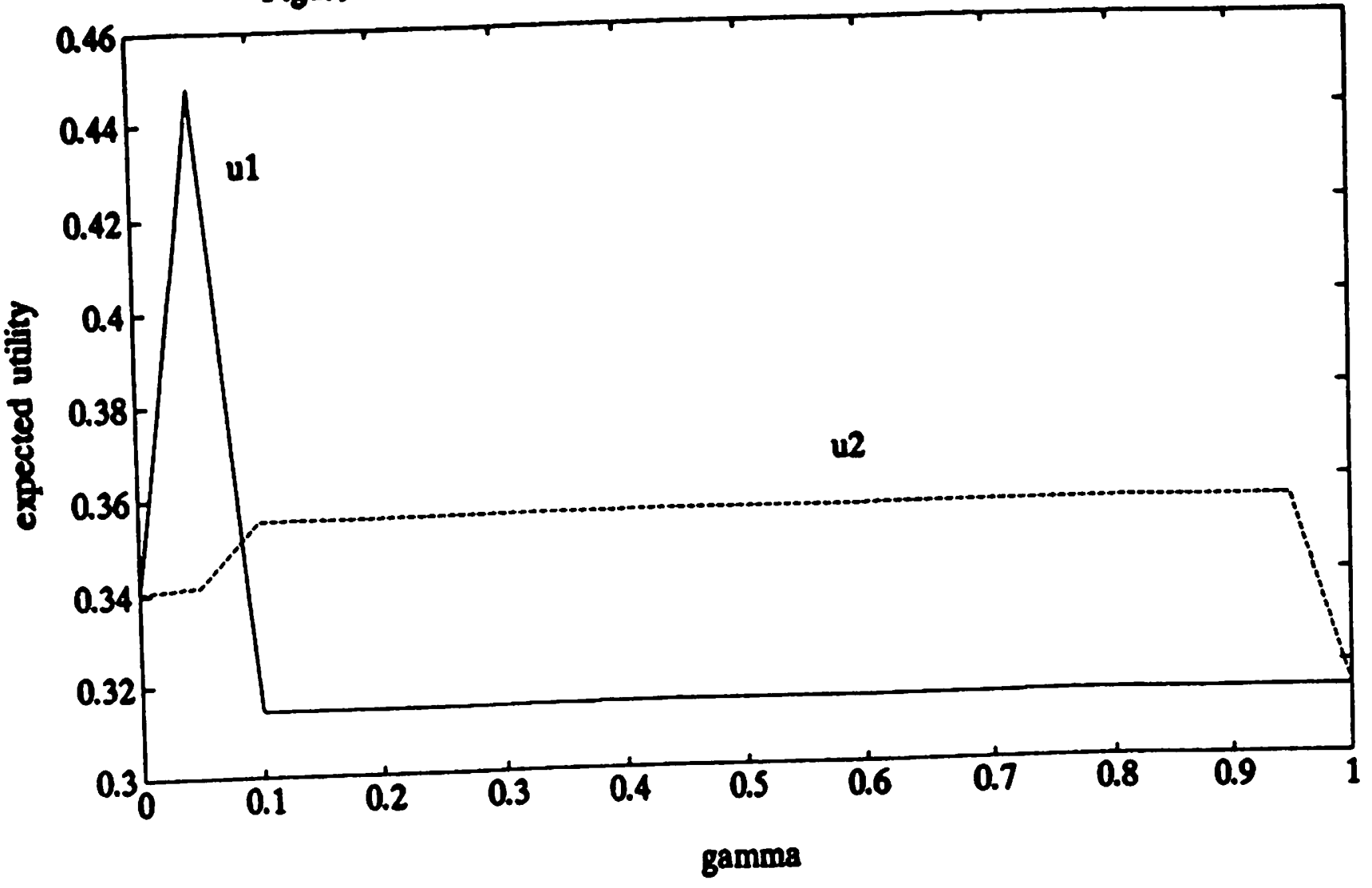

Figure 13: Constrained Equilibria, pi $=.1$, beta2 $=1.05$, alpha $=3$

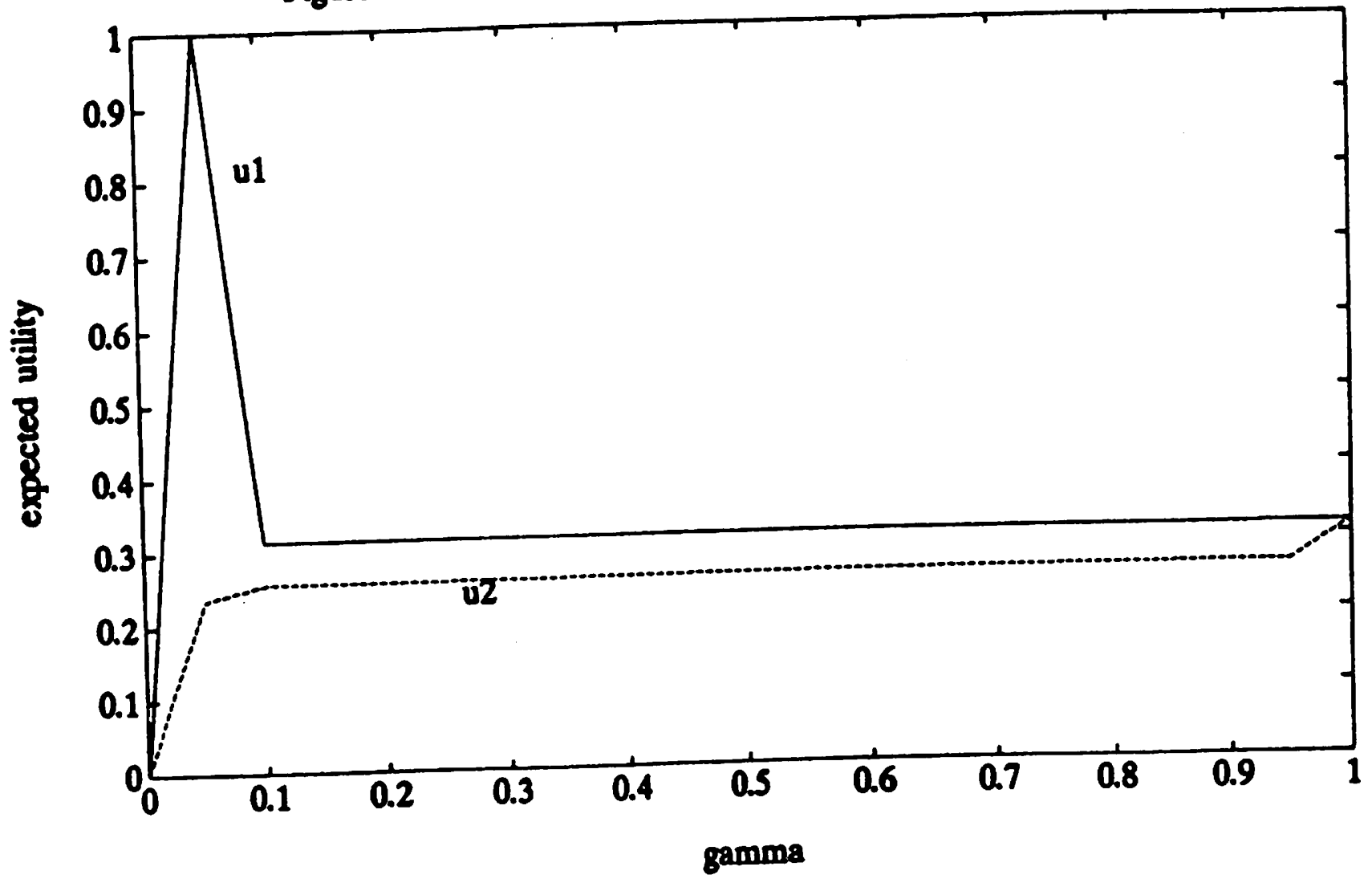




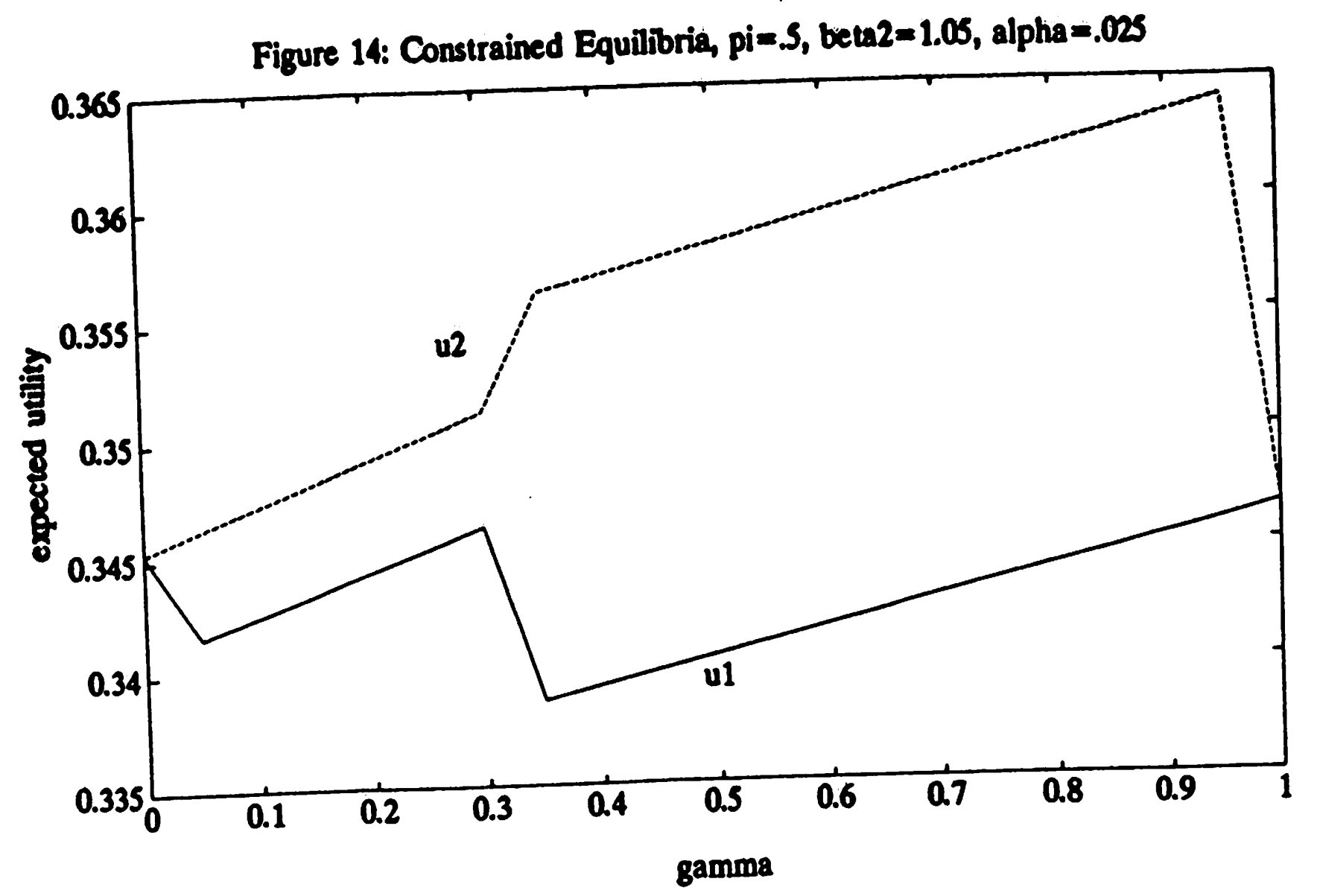

Figure 15: Constrained Equilibria, pi $=.5$, beta2 $=1.05$, alpha $=.04$

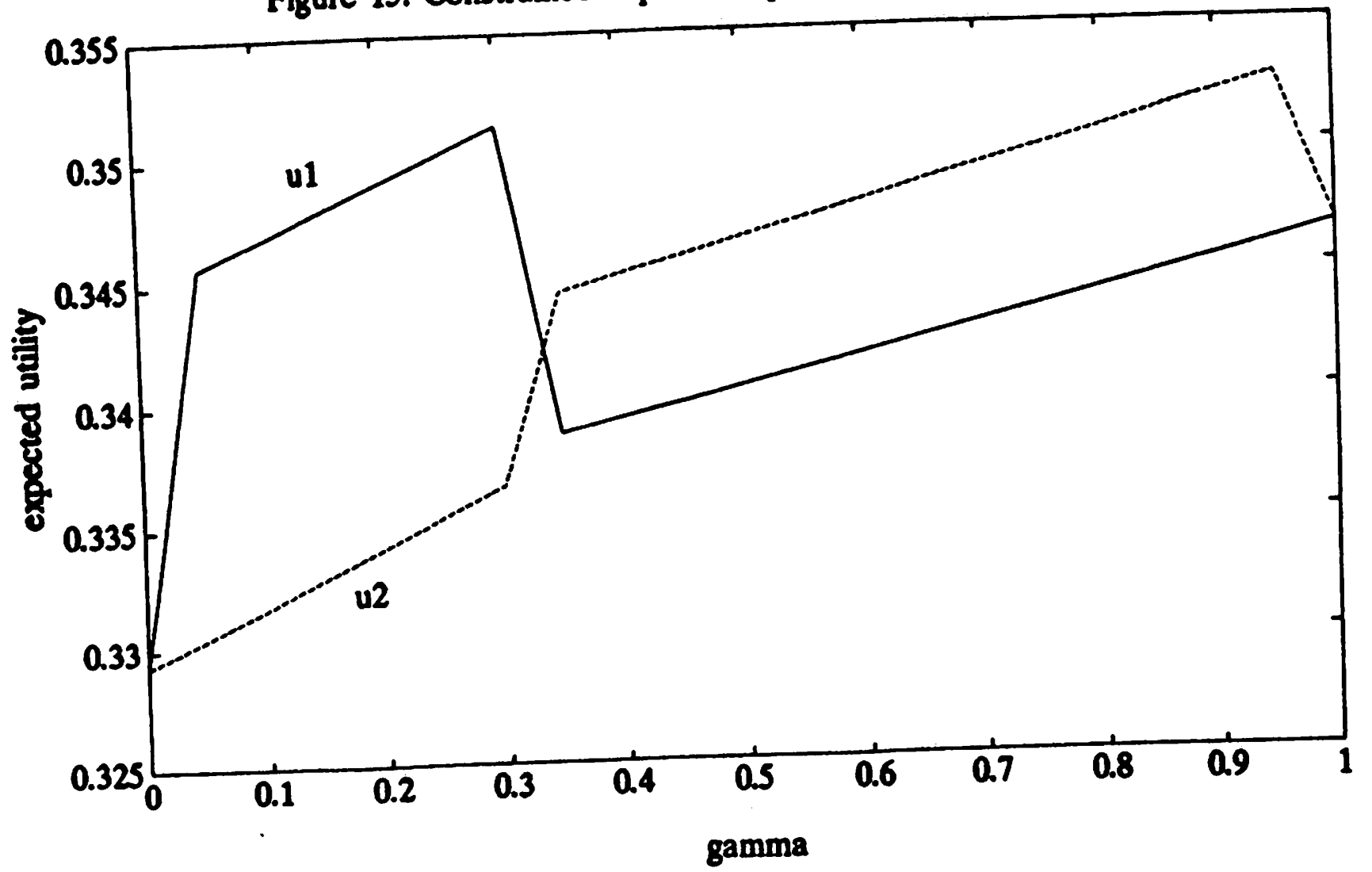




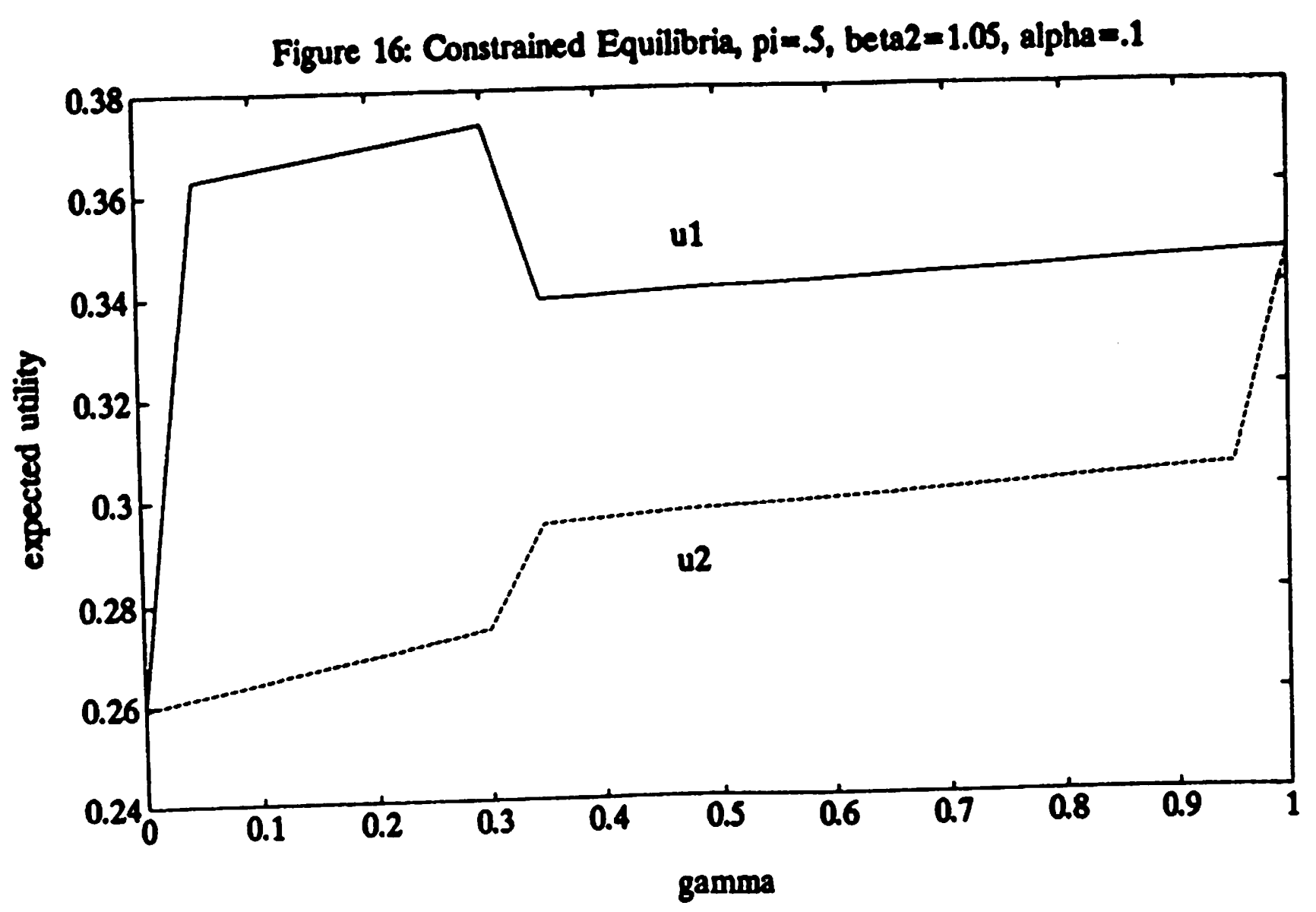

Figure 17: Constrained Equilibria, pi $=.9$, beta2 $=1.05$, alpha $=.001$

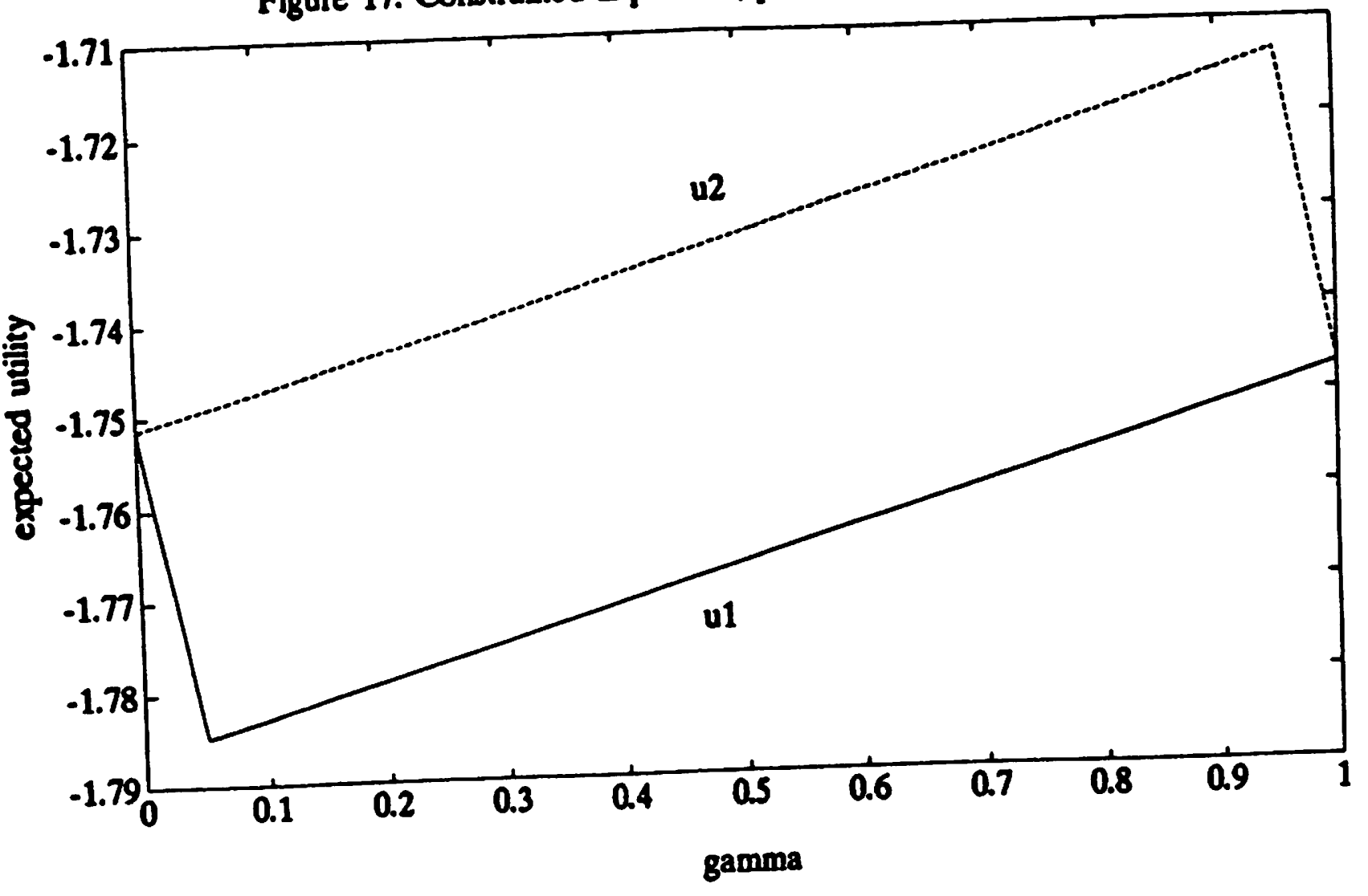


Figure 18: Constrained Equilibria, pi $=.9$, beta2 $=1.05$, alpha $=.005$

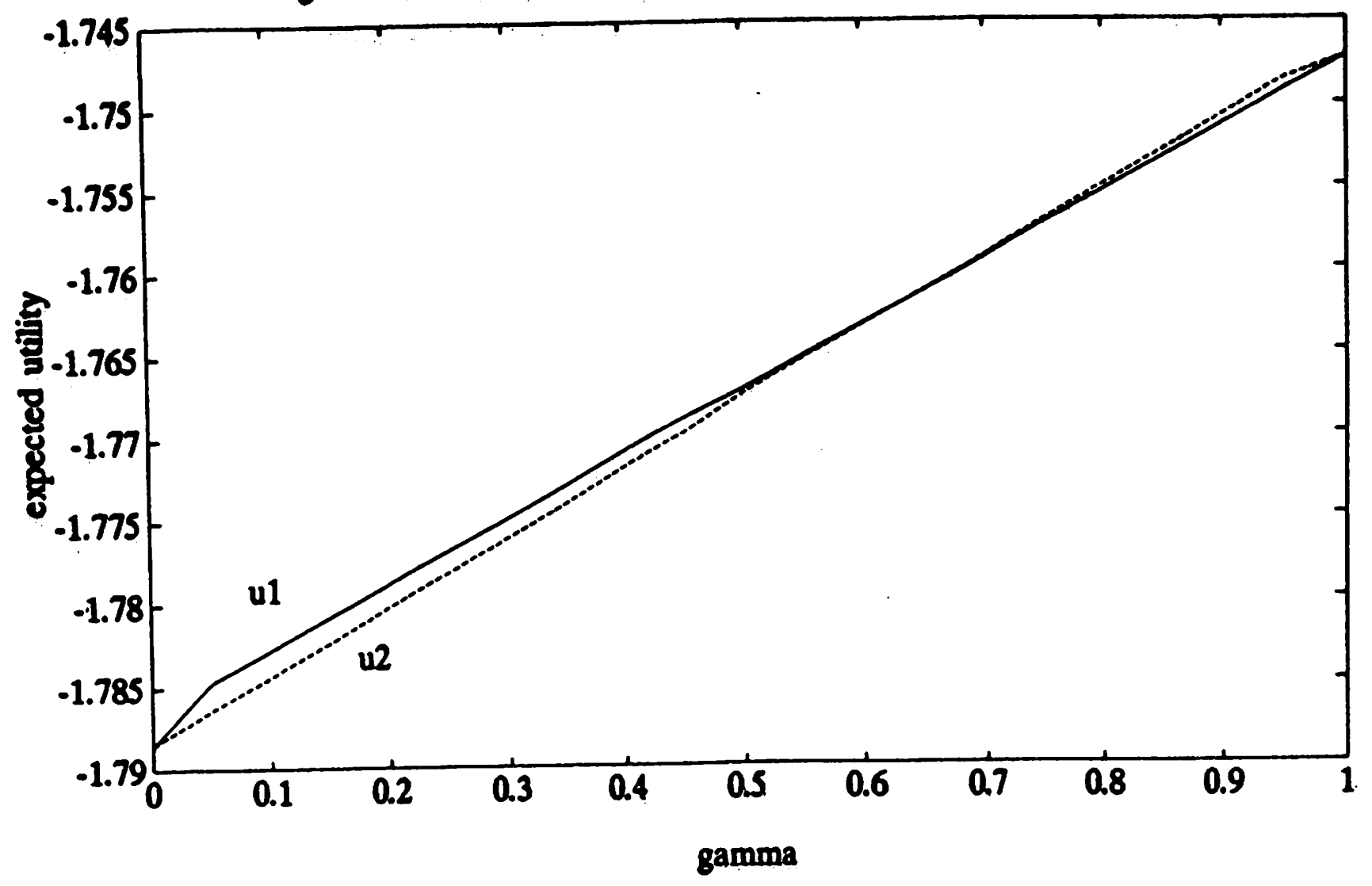

Figure 19: Constrained Equilibria, pi $=.9$, beta2 $=1.05$, alpha $=.01$

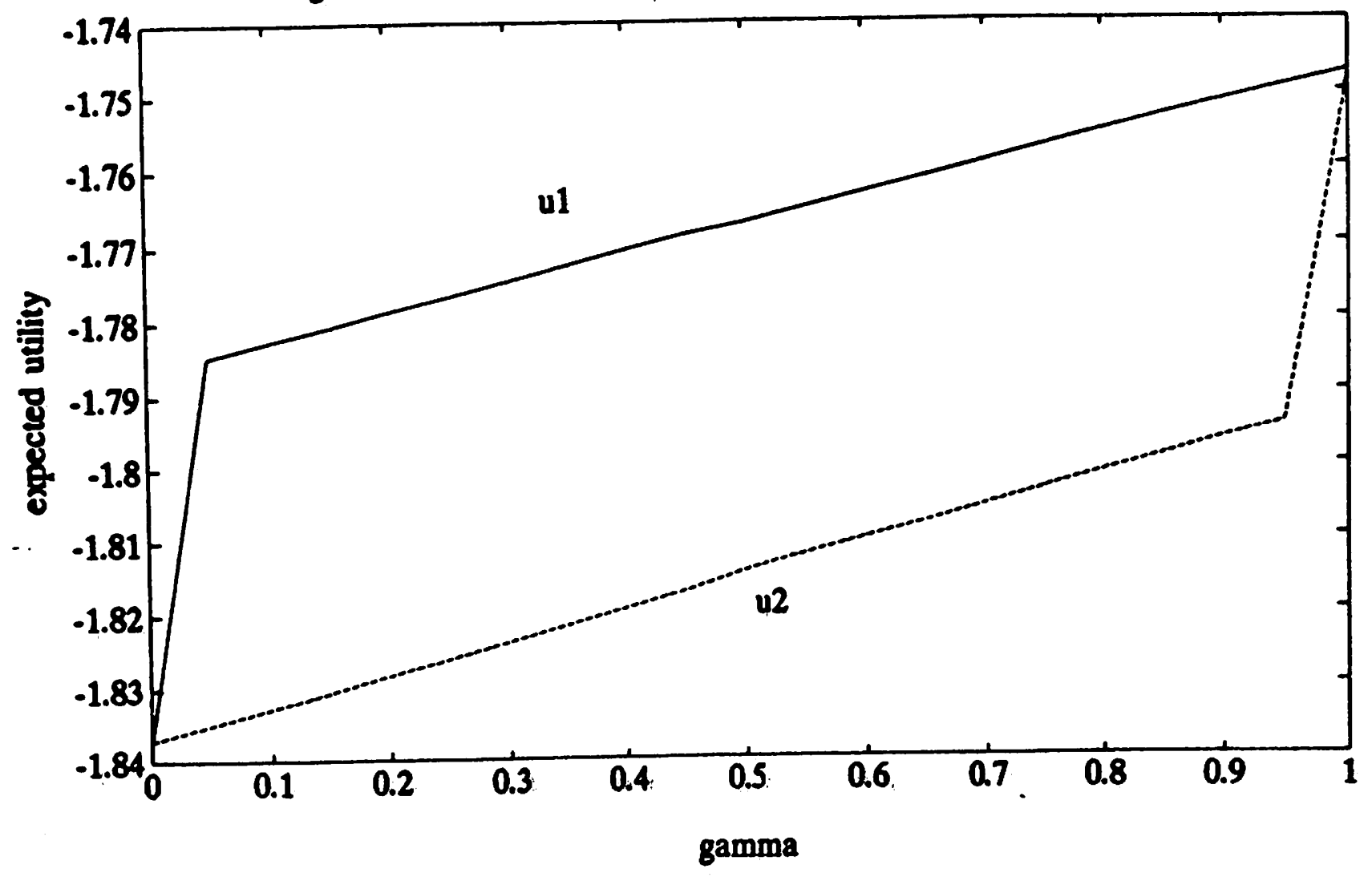

